\title{
¿ES FACTIBLE EL RESURGIMIENTO DEL CONFLICTO ARMADO EN COLOMBIA EN LA FASE DE POSCONFLICTO?*
}

\author{
Recibido: 07 de noviembre de 2017 • Aprobado: 29 de noviembre de 2017 \\ DOI: $10.22395 /$ seec.v21n46a3 \\ William Orlando Prieto** \\ Johanna Elizabeth Manrique ${ }^{* * *}$
}

\section{RESUMEN}

El objetivo de este artículo es presentar una revisión crítica sobre factores que pueden generar un resurgimiento del conflicto armado en la fase de posconflicto en Colombia. Para tal fin, se presenta una comparación de casos de África, Asia, Europa y América Latina en los últimos 10 años en torno a dos criterios: diseño de política pública durante el posconflicto; y resultados en desarrollo social antes y después de la firma de los acuerdos de paz. Dos conclusiones sobresalen: por un lado, la planeación de base comunitaria es relevante durante el periodo de reconstrucción social y económica; y por otro, los países con conflictos más antiguos parecen haber alcanzado un estado estacionario con consolidación de un sistema de violencia, particularmente en las zonas rurales. Para el caso colombiano, se puede decir que no es factible el resurgimiento del conflicto armado en la fase de posconflicto, siempre y cuando se realicen las respectivas inversiones en las dimensiones abordadas y sus variables -economía, capital humano, capital social, instituciones y desarrollo social-.

\section{PALABRAS CLAVE}

Negociación de conflictos; seguridad nacional y guerra; conflicto armado; resolución de conflictos; Colombia.

\section{CLASIFICACIÓN JEL}

D74, F51, H56

\section{CONTENIDO}

Introducción; 1. Política pública en posconflicto; 2. Estudios de caso; 3. Evidencia descriptiva; 4. Conclusiones; Bibliografía.

\footnotetext{
En el marco del reciente tratado de paz firmado con la guerrilla de las FARC en Colombia, este artículo pretende realizar una revisión de literatura en relación con los factores que se han identificado, y que pueden incidir en el resurgimiento del conflicto armado. Este artículo de investigación es producto del proyecto: "Causas estructurales de la violencia, mecanismos de política pública para reducir el riesgo de resurgimiento de violencia e implicaciones de política pública para el Postconflicto en Colombia", financiado por la Universidad Católica de Colombia y ejecutado durante 2016.

** Economista, Universidad Nacional de Colombia, Bogotá, Colombia. Magíster en políticas públicas, Universidad de Rochester, Nueva York, Estados Unidos. Docente investigador de tiempo completo, Facultad de Ciencias Económicas y Administrativas, Universidad Católica de Colombia, Bogotá, Colombia. Dirección: carrera 47 n. ${ }^{\circ}$ 13A-13, dirección postal 110231, oficina edificio C, tercer piso. Teléfono: 3203283452. Correo electrónico: woprieto@ucatolica.edu.co.

***Economista, Universidad Nacional de Colombia, Bogotá, Colombia. Magíster en ciencias económicas, Universidad Nacional de Colombia, Bogotá, Colombia. Docente investigadora, Facultad de Ciencias Económicas y Administrativas, Universidad Católica de Colombia, Bogotá, Colombia. Dirección: carrera 47 n. ${ }^{13 A}$ - 13, dirección postal 110231. Teléfono: 3124521458. Correo electrónico: jemanrique@ucatolica. edu.co.
} 


\section{IS THE RESURGENCE OF THE COLOMBIAN ARMED CONFLICT POSSIBLE IN THE POST-CONFLICT PHASE?}

\section{ABSTRACT}

This paper aims to present a critical review on factors that may cause a resurgence of the Colombian armed conflict in its post-conflict phase. For this purpose, a comparison of cases from Africa, Asia, Europe and Latin America in the last 10 years is presented around two criteria: The design of public policy during post-conflict, and the results in social development before and after the signing of the peace agreements. Two conclusions stand out: On the one side, community-based planning is relevant during the period of social and economic reconstruction; and on the other, countries with older conflicts seem to have reached a steady state that is accompanied by the consolidation of a system of violence, particularly in rural areas. In Colombia, it can be said that the resurgence of the armed conflict in the post-conflict phase is not feasible, provided that the respective investments are made in the dimensions addressed int the study and their variables (economy, human capital, social capital, institutions, and social development).

\section{KEYWORDS}

Conflict negotiation; national security and war; armed conflict; conflict resolution; Colombia.

\section{JEL CLASSIFICATION}

D74, F51, H56

\section{CONTENT}

Introduction; 1. Public policy in the post-conflict; 2. Case studies; 3. Descriptive evidence;

4. Conclusions; Bibliography.

\section{O RESSURGIMENTO DO CONFLITO ARMADO NA COLÔMBIA NA FASE DE PÓS- CONFLITO É FACTÍVEL?}

\section{RESUMO}

O objetivo deste artigo é apresentar uma revisão crítica sobre os fatores que podem gerar um ressurgimento do conflito armado na fase pós-conflito na Colômbia. Para tanto, apresenta-se uma comparação de casos da África, Ásia, Europa e América Latina nos últimos dez anos a partir de dois critérios: criação de política pública durante o pós-conflito; e resultados no desenvolvimento social antes e depois da assinatura dos acordos de paz. Duas conclusões se sobressaem: por um lado, o planejamento de base comunitária é relevante durante o período de reconstrução social e econômica; e, por outro, os países com conflitos mais antigos parecem ter alcançado um estado estacionário com consolidação de um sistema de violência, particularmente nas áreas rurais. Para o caso colombiano, pode-se dizer que o ressurgimento do conflito armado na fase pós-conflito não é factível, sempre e quando sejam realizados os devidos investimentos nas dimensões abordadas e suas variáveis - economia, capital humano, capital social, instituições e desenvolvimento social.

\section{PALAVRAS-CHAVE}

Negociação de conflitos; segurança nacional e guerra; conflito armado; resolução de conflitos; Colômbia.

\section{CLASSIFICAÇÃO JEL}

D74, F51, H56

\section{CONTEÚDO}

Introdução; 1. Política pública em pós-conflito; 2. Estudos de caso; 3. Evidência descritiva;

4. Conclusões; Bibliografia. 


\section{INTRODUCCIÓN}

El objetivo principal del presente documento es presentar una revisión crítica sobre posibles factores que pueden generar el riesgo de resurgimiento del conflicto armado en la fase de posconflicto, con énfasis en dos aspectos: 1), diseño de la política pública; y 2), resultados en los principales indicadores sociales antes y después de la firma de un acuerdo de paz. De esta manera, a través de una metodología de análisis comparativo de casos, y haciendo uso de literatura internacional, se exponen las principales innovaciones de política pública durante el posconflicto y los resultados en desarrollo social para 16 países (Afganistán, Armenia, Bosnia - Herzegovina, Camboya, Colombia, El Salvador, Guatemala, Haití, Kosovo, Liberia, Mozambique, Perú, Ruanda, Sierra Leona, Suráfrica, y Timor Leste), teniendo en cuenta los años de duración del conflicto y los años de duración del posconflicto.

La revisión de casos se realizó en torno a la evidencia de 54 documentos científicos publicados en revistas indexadas según el índice Scopus, y en documentos de política de organismos de cooperación internacional. Estos discuten las principales lecciones aprendidas, al tiempo que plantean algunas recomendaciones de política pública relevantes para la reconstrucción social implícita en el postconflicto.

El artículo se divide en cinco secciones (incluyendo la introducción). La primera discute el estado del arte de las políticas públicas implementadas durante el postconflicto en los países analizados. En la segunda, estos últimos se caracterizan según años en conflicto y posconflicto, al tiempo que se presentan los resultados en desarrollo humano que han acompañado las políticas implementadas una vez firmado los acuerdos de paz; esto último se realiza de acuerdo con una breve descripción histórica sobre la naturaleza del conflicto armado para cada país. Así entonces, el resultado de la segunda sección es una síntesis de los aspectos considerados relevantes para garantizar la estabilidad de los acuerdos de paz durante el postconflicto. La tercera sección, por su parte, contiene evidencia descriptiva acerca del desempeño económico, y los avances en inversión y capitales humano, social e institucional, en conjunto con los resultados más significativos en desarrollo social, en aras de correlacionar la caracterización de políticas con resultados tangibles en desarrollo social. La última sección presenta las principales conclusiones del documento.

\section{POLÍTICA PÚBLICA EN POSCONFLICTO}

La revisión crítica de literatura permite identificar evidencias en torno a las prácticas de políticas públicas para 16 países en postconflicto; se incluyen investigaciones tanto institucionales como académicas, publicadas durante los últimos 10 años en 
revistas indexadas y documentos de política de organismos de cooperación internacional. La revisión de documentos se elaboró sobre estudios de caso en África, Asia, Europa, y América Latina, con especial énfasis en estudios representativos de política pública orientados a mitigar la probabilidad de resurgimiento del conflicto.

\section{1. África}

En el caso particular de África, los documentos se pueden agrupar según énfasis en desarrollo institucional y desarrollo económico o humano. Algunos aspectos transversales son los mecanismos de desarme, desmovilización, reintegración y atención al trauma psicosocial del conflicto, los cuales son considerados factores críticos al momento de reducir la posibilidad de resurgimiento del conflicto armado. Los trabajos de Tobias y Boudreaux (2011), Englebert y Tull (2008), Collier (2009), Rugumamu y Gbla (2003), Kreimer et al. (2000a), y Kreimer et al. (2000b), presentan ejemplos relevantes de los desarrollos institucionales en las sociedades de posconflicto, caracterizados principalmente por la búsqueda de crecimiento económico, capital social y seguridad, en términos de las condiciones de desarme y las oportunidades de reinserción.

En lo que atañe a los aspectos más destacados en el desarrollo económico, sobresalen los trabajos de Tobias y Boudreaux (2011), Lynch et al. (2013), Ansoms (2005) y UNDP (2010). Los principales hallazgos giran en torno a la promoción del espíritu empresarial, la implementación de modelos de economías cooperativas para la explotación del café, el apoyo a la consolidación de microempresas, el impulso a la innovación en el cultivo urbano de alimentos y el diseño de una política económica orientada al crecimiento económico, con un enfoque de redistribución de recursos hacia la población más perjudicada por el conflicto armado.

Desde una perspectiva financiera del desarrollo económico, Lemmon (2012) enfatiza en los efectos económicos positivos de facilitar el acceso a crédito en condiciones de sostenibilidad empresarial. Dichas condiciones están asociadas a la existencia de planes de inversión viables, el acceso a mercados, la conectividad a redes empresariales y la capacitación en competencias empresariales claves. Algunas de esas habilidades aluden al mantenimiento de registros, habilidades de comercialización de productos y destrezas en su venta.

En lo que concierne al desarrollo humano, la sostenibilidad e impulso a la igualdad de género, a partir de la identificación del impacto sobre los roles de género afectados por el conflicto armado, es el aspecto central del caso de estudio presentado por Smet (2009) en Sierra Leona. Dicho estudio ofrece evidencia sobre la 
necesidad de cambios legislativos, con especial énfasis en la abolición de prácticas discriminatorias. En la misma vía, Massaquoi (2007) explora el enfoque de derechos para la población femenina en Libia como una estrategia social orientada a la reconstrucción y mejoramiento de las instituciones que conforman el estado en posconflicto.

Lo anterior es complementado por Akresh, Verwin y Bundervoet (2011): indagan por la correlación existente entre la destrucción de cosechas durante el conflicto y las consecuencias perjudiciales del mismo en los niños, particularmente en lo que concierne a la salud y educación. Tal destrucción conlleva resultados sociales y económicos desfavorables que limitan el avance en materia de desarrollo humano, en términos del desarrollo biológico y cognitivo de los infantes.

En el ámbito teórico, sobresale el trabajo de Ali (2009): dicha investigación plantea un modelo alternativo de desarrollo para los países en posconflicto, elaborado sobre la teoría del desarrollo como libertad planteada por Sen (1999). El modelo sugiere cuatro dimensiones: la especificación de un objetivo de desarrollo; la identificación de los mecanismos de distribución de la riqueza; la identificación de una política de crecimiento pro-pobre; y la especificación de los requerimientos de ayuda internacional.

\subsection{Asia y Europa}

Según la literatura revisada para el caso de estos dos continentes, la reconstrucción social durante el posconflicto hace uso de cuatro estrategias:

- Alternativas de generación de empleo

- Estrategias de diseño institucional para favorecer la coordinación de donantes

- Estrategias de reconstrucción institucional con participación ciudadana,

- Estrategias de reconstrucción del sistema financiero

En las experiencias relacionadas con alternativas de generación de empleo sobresale el estudio del Banco Mundial (2005) realizado en Afganistán, en el que se resaltan las inversiones en obras públicas y fortalecimiento de la comunidad como aquellas con los retornos sociales más altos. Lo anterior concuerda con los hallazgos de Lyer y Santos (2012) en un estudio sobre las alternativas con mayor creación de empleo en sistemas productivos de sociedades asiáticas en postconflicto, en la medida en que se defiende la importancia de los proyectos de inversión en obras públicas para el empleo de la mano de obra no calificada reinsertada. 
En el ámbito institucional, sobresale la descripción realizada por Ohayan (2002) acerca de la creación de estructuras institucionales para facilitar el manejo de los recursos de donantes internacionales. La relevancia de la coordinación de actividades en las etapas de diseño, financiación y ejecución de estrategias de reconstrucción, articuladas con los recursos de los donantes internacionales, es subrayada como una estrategia necesaria para la reconstrucción bajo el modelo de microfinanzas en Bosnia y Herzegovina.

En lo referido a la participación ciudadana, un proyecto participativo elaborado por Garstka (2010) sobre formalización de barrios ilegales en Kosovo, presenta evidencia para entender los mecanismos de interacción entre los donantes internacionales y las organizaciones comunitarias. Los arreglos institucionales con participación ciudadana permitieron un uso efectivo de los recursos económicos provistos por los donantes internacionales, en tanto se alcanzaron beneficios propios de la formalización para los habitantes del barrio, víctimas y reinsertados del conflicto armado en Kosovo. Del mismo modo, Wei (1996) resalta ventajas similares sobre la participación financiera en los proyectos de reconstrucción social para financiar proyectos participativos. En la misma perspectiva, Haynes (2010) y el Banco Mundial (2010) resaltan la necesidad de desarrollar liderazgo, particularmente de la población femenina, como elemento esencial para garantizar la sostenibilidad y éxito de los proyectos de reconstrucción en postconflicto.

En lo que atañe a la estrategia con apoyo directo ensamblando instituciones financieras, sobresale el trabajo de McMahon (2004). Según el estudio, las inversiones realizadas en Bosnia-Herzegovina fueron priorizadas en torno a tres aspectos: lograr un acuerdo sostenible entre las partes en discordia; reconstruir y mejorar las estructuras del gobierno; y garantizar el resurgimiento y funcionamiento del sistema financiero.

\subsection{América Latina}

Dentro de las estrategias con énfasis en arreglos institucionales en América Latina, sobresalen las experiencias en El Salvador, Guatemala y Colombia. Los orígenes del conflicto en esta región están más asociados a las disparidades económicas y, por tanto, los estudios enfatizan en el desarrollo económico y al desarrollo institucional. Se destaca el trabajo de Eriksson, Kreimer y Arnold (2000) sobre la experiencia del posconflicto en El Salvador, en la cual los arreglos institucionales sobresalen como un conjunto de arreglos de coordinación de política económica que explican la estabilidad macroeconómica, necesaria para impulsar el crecimiento económico. 
La interpretación de desarrollo institucional es interpelada por las aproximaciones microeconómicas, claves en la consolidación del proceso de paz. Por ejemplo, Tabak (2011) reflexiona sobre la imperfección de las estrategias de reconstrucción, en la medida en que existen deficiencias en la implementación de sistemas transicionales de justicia, especialmente en lo que concierne a los derechos de las mujeres.

Asimismo, teniendo en cuenta las diferencias significativas en términos de los distintos tipos de violencia (física, emocional, y sexual), es necesario un enfoque micro, para el cual se requieren distintos tipos de programas con enfoque de género. Las oportunidades para las mujeres, aunque importantes en sí mismas, no conllevan cambios en masculinidad, en relaciones patriarcales, ni en inequidades de género al interior del hogar. Por lo tanto, es necesario incluir dimensiones de la política pública relacionadas con relaciones maritales, distribución del tiempo, trabajo y finanzas, y redes sociales familiares y no familiares.

Resulta relevante evitar la mercantilización de la tragedia de las víctimas del conflicto armado, asegurando mecanismos adecuados y transparentes de apoyo, y evitando la revictimización. Los trabajos de Erica (2010), Menjívar y Agadjanian (2007), desarrollados en Haití y Guatemala, presentan investigaciones relacionadas con los distintos tipos de violencia y la posibilidad de mercantilización y revictimización durante el posconflicto. Lo anterior es similar a las conclusiones alcanzadas por Finoff (2012) en el caso de estudio de Ruanda, lo cual es esclarecedor en cuanto a la importancia de estos elementos para el diseño de política pública.

Para Kumar, Baldwin y Benjamin (2000), un desarrollo institucional adecuado permite integrar proyectos institucionales a otros de orden superior, los cuales mejoran el alcance social a través de comunicación organizada, multilateral y coordinada. Al mismo tiempo, dichas redes de proyectos de distinto orden fomentan alianzas público-privadas en asocio con las organizaciones de base comunitaria de mujeres, sindicatos y comerciantes informales. De esta manera, el desarrollo institucional se caracteriza, principalmente, por facilitar los procesos de planeación participativa, con redes especializadas encaminadas a facilitar la implementación de una estrategia multiétnica de paz. Lo anterior concuerda con los estudios en África, Asia y Europa descritos en los trabajos de Tarway-Talla (2011), Fred-Mensah (2004), Ohanyan (2002) y Justino (2011), y Dursun-Ozkanca (2009), respectivamente.

Por otro lado, en el ámbito del desarrollo económico, sobresale el estudio de la OIT (2010). Esa investigación plantea una exploración comparativa de la recuperación económica local (REL) en condiciones de posconflicto. La REL depende de manera crítica de la generación de empleo; y para garantizarla en condiciones dig- 
nas, es necesario facilitar la implementación del enfoque de trabajo decente en lo que concierne a las características de empleo productivo, justamente remunerado, realizado en condiciones de equidad, seguridad y libertad, y con respecto a la dignidad humana.

A pesar de la relevancia del empleo, es indispensable considerar la propiedad de la tierra como factor potenciador de la violencia, en la medida en que condiciona el funcionamiento del mercado de trabajo - particularmente en Colombia-. En esta vía, Thomson (2011) sugiere la relevancia de la concentración en la propiedad de la tierra como factor desestabilizador de los procesos de paz en Colombia. Lo anterior parece indicar, como lo señala Thorsell (2013), la inefectividad de los estímulos al emprendimiento en un modelo de corte neoliberal en la generación de ingresos y en la provisión de seguridad económica, debido a la existencia de brechas de concentración de la riqueza significativas. Lo anterior es complementado por Vélez y Insuasty (2017), quienes señalan la necesidad de comprender el funcionamiento del territorio, además de la propiedad de la tierra, para garantizar un modelo de economía mixta adecuado al desarrollo comunitario.

En la misma vía propositiva, la Comisión del Conflicto y sus Víctimas señala aspectos esenciales para el logro de un proyecto de posconflicto exitoso en Colombia. Dentro de estos resalta la necesidad de un modelo económico más incluyente; el fortalecimiento del Estado en lo que atañe a los servicios de justicia y presencia de la policía nacional; la desarticulación de la parapolítica; la economía de la guerra; el narcotráfico; y la minería ilegal.

En resumen, la revisión crítica de literatura permitió establecer algunos puntos de encuentro en las prácticas de política pública en el posconflicto. Tres aspectos se destacan en los estudios de caso presentados: la relevancia de las condiciones históricas; la construcción endógena del posconflicto (participación ciudadana); y la ocurrencia de condiciones vinculantes de los acuerdos alcanzados, en términos de capital social y seguridad.

En términos generales, los estudios de caso identifican cinco factores potenciales relevantes en el diseño de política pública, con la consecuente disminución de la probabilidad de resurgimiento del conflicto en un ciclo de violencia:

- Fortalecimiento institucional

- Generación de capacidad local (individual y social)

- Priorización de la inversión social 
- Inversión en seguridad

- Inversión en capital humano

Lo anterior promueve el desarrollo y funcionamiento del trabajo formal. Durante el posconflicto, este compite de manera paralela por fuerza laboral con un mercado del crimen, en zonas geográficas caracterizadas por altos niveles de pobreza, altos niveles de concentración del ingreso y recursos económicos, así como por un interés económico definido (minería ilegal, rutas de comercialización de narcóticos en Colombia) o uno político preestablecido (parapolítica en Colombia).

La descripción de los aspectos de política pública responde a una caracterización del conflicto, según las condiciones específicas de cada caso. Lo anterior está ligado a las causas del conflicto, que en términos teóricos pueden agruparse en dos grandes grupos. Por un lado, se encuentran las causas objetivas, asociadas a las explicaciones de la teoría económica y señaladas por la existencia de condiciones estructurales en términos de desigualdad de ingresos, alto desempleo rural -en especial para la población joven-, persecución de líderes sindicales y concentración en la propiedad de la tierra, entre otros aspectos; y por otro, existen las causas subjetivas, asociadas a las explicaciones de la teoría política, la cual enfatiza en la decisión subjetiva de utilizar la violencia como mecanismo para reemplazar un modelo de desarrollo económico y social vigente. Los trabajos de Collier, Hoeffler y Soderbom (2004), Collier, Hoeffler y Rohner (2008), así como la relatoría de la Comisión de Conflicto y sus Víctimas presentada en febrero de 2015, describen la composición de las explicaciones teóricas respecto de la ocurrencia del conflicto. Lo anterior señala, como lo hacen Nasi y Rettberg (2005), y Randall (2005), la necesidad de incorporar en el análisis las singularidades del conflicto para comprender las elecciones de política pública, y la manera como se relacionan con los marcos teóricos señalados.

\section{METODOLOGÍA: ESTUDIOS DE CASO}

Con el objeto de realizar un seguimiento descriptivo a los factores señalados como prioritarios en la literatura revisada se realizó un análisis de 16 países cuyas situaciones corresponden a experiencias de sociedades en posconflicto: Afganistán, Armenia, Bosnia-Herzegovina, Camboya, Colombia El Salvador, Guatemala, Haití, Kosovo, Liberia, Mozambique, Perú, Ruanda, Sierra Leona, Suráfrica y Timor Leste. Las naciones estudiadas firmaron acuerdos de paz desde principios de la década de 1990 frente a conflictos armados internos cuyo rango de duración osciló entre 3 y 44 años; se excluye de esto último el conflicto en Colombia, que inició en 1964 
y alcanzó 50 años de duración cuando se firmó el acuerdo de paz con las Fuerzas Armadas Revolucionarias de Colombia (FARC).

Tabla 1. Países en postconflicto

\begin{tabular}{|c|c|c|c|c|c|c|c|}
\hline \multirow{2}{*}{ País } & \multicolumn{2}{|c|}{ Conflicto } & \multirow{2}{*}{ Acuerdo } & \multirow{2}{*}{$\begin{array}{l}\text { Años en } \\
\text { conflicto }\end{array}$} & \multirow{2}{*}{$\begin{array}{c}\text { Años en } \\
\text { posconflicto }\end{array}$} & \multirow{2}{*}{$\begin{array}{c}\text { Porcentaje de } \\
\text { población rural }\end{array}$} & \multirow{2}{*}{$\begin{array}{l}\text { IDH } \\
2012\end{array}$} \\
\hline & Comienzo & Final & & & & & \\
\hline Afganistán & 1981 & 2001 & Bonn & 21 & 14 & 76 & 0,374 \\
\hline Armenia & 1988 & 1994 & Grupo Minsk & 7 & 21 & 36 & 0,729 \\
\hline $\begin{array}{l}\text { Bosnia y } \\
\text { Herzegovina }\end{array}$ & 1992 & 1995 & $\begin{array}{l}\text { Acuerdos de Dayton } \\
\text { París }\end{array}$ & 4 & 20 & 51 & 0,735 \\
\hline Camboya & 1967 & 1990 & $\begin{array}{l}\text { La Organización de } \\
\text { Naciones Unidas } \\
\text { (ONU) elaboró un } \\
\text { plan de paz. }\end{array}$ & 24 & 25 & 80 & 0,543 \\
\hline Colombia & 1964 & 2013 & $\begin{array}{l}\text { En conversaciones: } \\
\text { "Acuerdo general } \\
\text { para la terminación } \\
\text { del conflicto y } \\
\text { construcción de paz } \\
\text { estable y duradera" }\end{array}$ & 50 & 0 & 24 & 0,719 \\
\hline El Salvador & 1980 & 1992 & $\begin{array}{l}\text { Acuerdos de Paz de } \\
\text { Chapultepec }\end{array}$ & 13 & 23 & 35 & 0,68 \\
\hline Guatemala & 1960 & 1996 & $\begin{array}{l}\text { Acuerdo de } \\
\text { Esquipulas, Acuerdo } \\
\text { de Querétaro, } \\
\text { acuerdo de paz firme } \\
\text { y duradera }\end{array}$ & 37 & 19 & 50 & 0,581 \\
\hline Haití & 1987 & 2004 & $\begin{array}{l}\text { Pacto de consenso } \\
\text { sobre la transición } \\
\text { política }\end{array}$ & 18 & 11 & 45 & 0,456 \\
\hline Kosovo & 1996 & 1999 & $\begin{array}{l}\text { Conferencia de } \\
\text { Rambouillet, París }\end{array}$ & 4 & 16 & & \\
\hline Liberia & 1989 & 2003 & $\begin{array}{l}\text { Misión de Naciones } \\
\text { Unidas }\end{array}$ & 15 & 12 & 51 & 0,388 \\
\hline Mozambique & 1977 & 1992 & $\begin{array}{l}\text { Acuerdo de Paz, } \\
\text { ONU }\end{array}$ & 16 & 23 & 69 & 0,327 \\
\hline Perú & 1980 & 2000 & Sin acuerdos de paz & 21 & 15 & 22 & 0,741 \\
\hline
\end{tabular}


¿Es factible el resurgimiento del conflicto armado en Colombia en la fase de posconflicto?

\begin{tabular}{|c|c|c|c|c|c|c|c|}
\hline \multirow{2}{*}{ País } & \multicolumn{2}{|c|}{ Conflicto } & \multirow{2}{*}{ Acuerdo } & \multirow{2}{*}{$\begin{array}{l}\text { Años en } \\
\text { conflicto }\end{array}$} & \multirow{2}{*}{$\begin{array}{c}\text { Años en } \\
\text { posconflicto }\end{array}$} & \multirow{2}{*}{$\begin{array}{c}\text { Porcentaje de } \\
\text { población rural }\end{array}$} & \multirow{2}{*}{$\begin{array}{l}\text { IDH } \\
2012\end{array}$} \\
\hline & Comienzo & Final & & & & & \\
\hline Ruanda & 1990 & 1994 & $\begin{array}{l}\text { Acuerdos de Arusha, } \\
\text { Genocidio de } \\
\text { Ruanda, Misión de } \\
\text { la ONU }\end{array}$ & 5 & 21 & 81 & 0,434 \\
\hline Sierra Leona & 1991 & 2002 & $\begin{array}{l}\text { Acuerdo de Paz de } \\
\text { Lomé, Operación } \\
\text { Palliser }\end{array}$ & 12 & 13 & 60 & 0,359 \\
\hline Sur África & 1948 & 1991 & $\begin{array}{l}\text { Desmantelamiento } \\
\text { del Apartheid }\end{array}$ & 44 & 24 & 38 & 0,629 \\
\hline Timor Leste & 1976 & 2002 & Misión de la ONU & 27 & 13 & 71 & 0,576 \\
\hline Promedio & 1979 & 1998 & & 20 & 17 & 52,6 & 0,551 \\
\hline Mediana & 1980 & 1997 & & 17 & 18 & 51 & 0,576 \\
\hline
\end{tabular}

Fuente: elaboración propia con base en indicadores mundiales del Banco Mundial para porcentaje de población rural 2012, y Naciones Unidas para el Índice de Desarrollo Humano (IDH) 2012.

Los países en posconflicto registran un índice de desarrollo humano (IDH) promedio de 0,55 a 2012; una proporción promedio de población rural cercana a la mitad de la población total; y un número promedio de años en posconflicto inferior en tres años al promedio de tiempo en conflicto. Bosnia y Herzegovina registran los IDH más altos, mientras que Sierra Leona y Mozambique registran los más bajos. Por otro lado, Afganistán, Camboya, Colombia, El Salvador, Guatemala, Haití, Liberia, Mozambique, Perú, Sierra Leona, Suráfrica y Timor Leste ostentan, en promedio, un IDH de 0,53, con conflictos armados de más de 10 años.

Frente al promedio, Colombia presenta una menor población rural y un IDH superior. Desde 1989 hasta 1993, con una pausa en 1991, Colombia ha estado técnicamente en un conflicto armado intermedio. El criterio utilizado para clasificarlo sigue el planteado por Colleta et al. (2000): esto es, aquel por el que se clasifica un conflicto armado en función del número de muertes en batalla. En tal sentido, un conflicto armado mayor, o guerra civil, ocurre cuando existen más de 1000 muertes en batalla por año. En esta misma vía, un estudio desarrollado por el Programa de las Naciones Unidas para el Desarrollo - PNUD (2011) y el Centro de Recursos para el Análisis de Conflictos (Cerac) señala un total de víctimas fatales de 218.094 desde 1958 hasta 2012. Del total de víctimas, 81\% fueron civiles (178.837 personas) y $18 \%$ combatientes ( 39.257 personas), lo que equivale a una tasa promedio anual total de 3.965 víctimas. Aunque el total de víctimas de muertos en combate (713 
muertos por año) es inferior al umbral declarado por Coletta et al. (2000), la Comisión Histórica del Conflicto y sus Víctimas declaró al conflicto armado en Colombia como atroz en febrero de 2015, teniendo en cuenta los efectos negativos del conflicto armado sobre la población civil.

Así mismo, desde 1982 hasta 2013, ocho administraciones públicas han realizado distintos esfuerzos por alcanzar o controlar la violencia generada por el conflicto armado. Sobresale en este sentido el gobierno de Juan Manuel Santos Calderón (2010-2018) en tanto que, por primera vez en las últimas tres décadas de administraciones elegidas democráticamente (posteriores al periodo del llamado Frente Nacional), el gobierno de la República de Colombia y las FARC firmaron el "Acuerdo general para la terminación del conflicto y la construcción de una paz duradera". Este último fue puesto a consideración en un plebiscito en octubre de 2016 con un resultado adverso, lo cual conllevó a la inclusión de observaciones planteadas por la representación política de quienes expresaron democráticamente no estar de acuerdo con lo pactado. El acuerdo definitivo se firmó en noviembre de 2016. Asimismo, durante esta administración, se iniciaron conversaciones con el Ejército de Liberación Nacional (ELN) en octubre de 2016.

En El Salvador, el acuerdo de paz se firmó en 1992, tras un conflicto que duró más de 12 años y que costó la vida a más 70.000 personas. Por otro lado, según Richani (2010), al lograrse la firma del acuerdo respectivo en Guatemala, 375.000 personas permanecían sin empleo; ello condujo a una importante y contraproducente interdependencia entre fuerza laboral disponible, fuerzas militares y organizaciones criminales. Asimismo, al igual que en Perú -en donde, según Laplante (2007), no se firmó un acuerdo de paz-, El Salvador y Guatemala llevaron a cabo comisiones de la verdad con amnistía, en un enfoque de justica retributiva centrado en indemnizar a las víctimas del conflicto armado.

En Colombia, el acuerdo sobre víctimas describe la composición de un Sistema Integral de Verdad, Justicia, Reparación y No Repetición. Entre sus componentes se encuentran la Comisión para la el Esclarecimiento de la Verdad, la Unidad de Búsqueda de Personas Desaparecidas, la Jurisdicción Especial para la Paz, las medidas de reparación integral y las garantías de no repetición.

En Sierra Leona la guerra no fue motivada por razones étnicas, como ocurrió en Ruanda; sin embargo, presenta delitos de guerra igualmente atroces y frecuentes en los conflictos internos, tales como reclutamiento de menores, mutilación, tortura, asesinatos indiscriminados de civiles y destrucción de propiedad privada. Según Amman y O'Donnell (2011), una estimación preliminar sugiere un total de 50.000 personas muertas, 100.000 mutilados, 250.000 mujeres violadas y 2 millo- 
nes de personas obligadas a migrar de las zonas rurales hacia la capital del país, lo cual ha ocasionado sobrepoblación y cuellos de botella en la oferta de servicios públicos. Por su parte, Finnoff (2012) describe la manera como en Ruanda la violencia ha sido un aspecto recurrente entre las dos minorías étnicas más importantes -hutus y tutsis-.

La independencia de Portugal por parte de Mozambique, acaecida en 1975, originó una guerra de guerrillas que terminaría cerca de 17 años después, en 1992, con la firma del acuerdo de paz en Roma (Fred-Mensah, 2004). Asimismo, dos décadas después del inicio del conflicto en Afganistán, en 2001, comenzó un proceso político para encontrar una salida. Al final del régimen talibán, en 2001, el conflicto había cobrado la vida de más de un millón de afganos (AIF, 2007).

La tabla 2 presenta un análisis comparativo entre el caso colombiano y las experiencias, características y alternativas que proponen algunos autores para los casos del El Salvador, Guatemala, Haití, y Bosnia-Herzegovina. Como puede observarse, en el aspecto de seguridad es frecuente encontrar en el posconflicto la falta de un sistema lo suficientemente fuerte como para minimizar el período de reconstrucción necesario para la paz.

En el ámbito económico, la recuperación a corto plazo depende del daño causado a los activos físicos del país. La magnitud del desplazamiento, que conlleva altos niveles de desempleo y subempleo, ha sido atendida con programas de reintegración implementados sobre la base comunitaria, con el objeto de articular los sistemas productivos comunitarios a los locales, regionales y nacionales. Dicha estrategia ha generado más confianza en la reconstrucción y sostenibilidad de la paz.

Por su parte, la legitimidad institucional es caracterizada por respuestas inmediatas con mayor inversión social, generación de empleo de emergencia y control y reducción de los problemas de tráfico de drogas armas y piratería, los cuales están en la base de las organizaciones criminales en las zonas de conflicto. En los ámbitos de desminado y desarme, y justicia y la reparación, se requieren esfuerzos institucionales relevantes para lograr una firma de acuerdo de paz con desarme y desminado, con un enfoque de justicia transicional.

\section{EVIDENCIA DESCRIPTIVA}

Para contrastar la evolución de los aspectos señalados en la tabla 2, se realiza un análisis descriptivo de las 16 sociedades en posconflicto, en el que se emplean cuatro categorías epistemológicas: desempeño de la economía, capital humano, capital social y resultados en desarrollo social. 


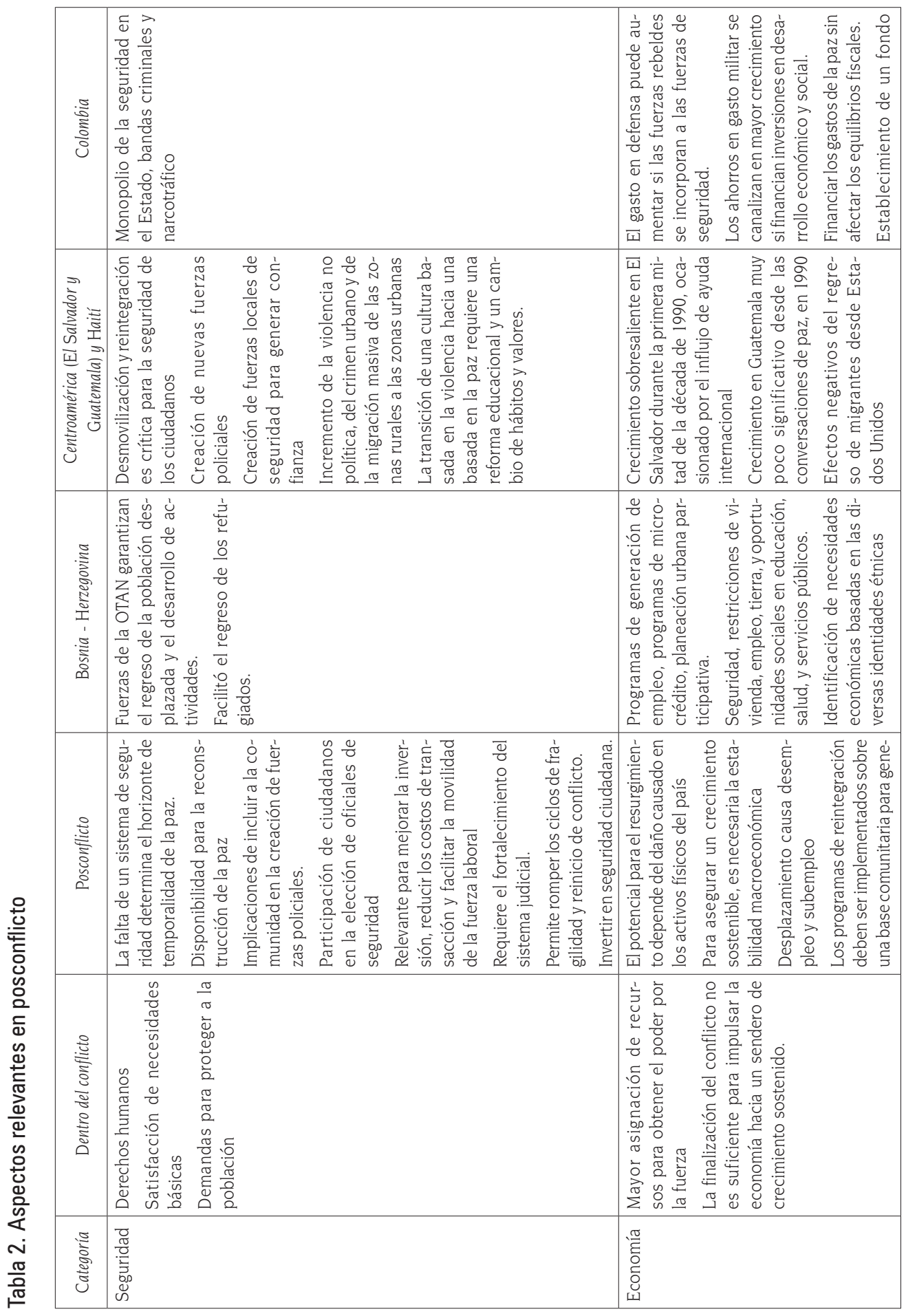




\begin{tabular}{|c|c|c|c|c|c|}
\hline & & 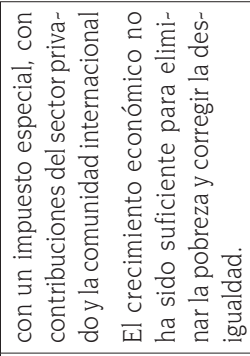 & 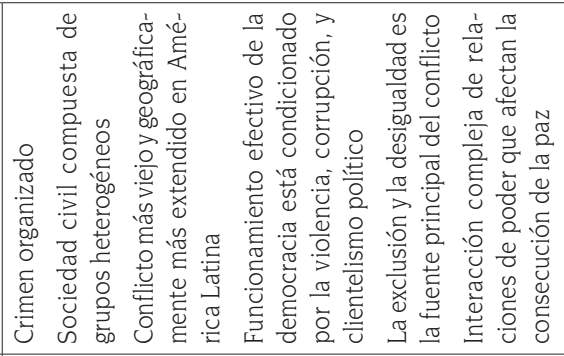 & 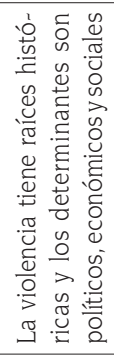 & 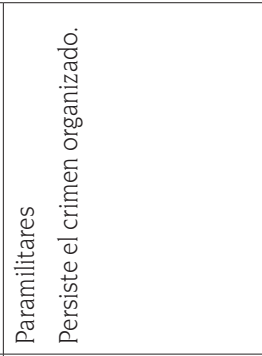 \\
\hline & & 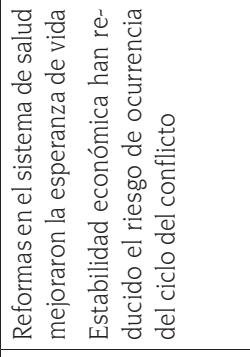 & 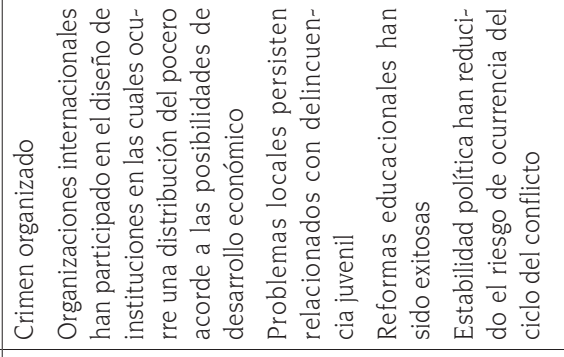 & & 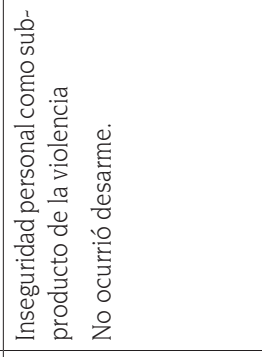 \\
\hline & & 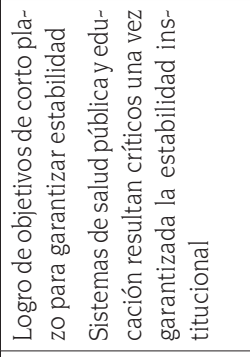 & 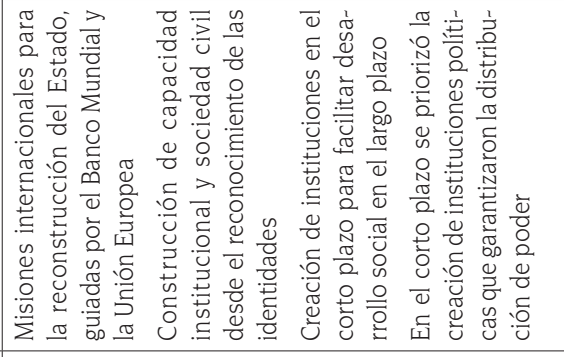 & & 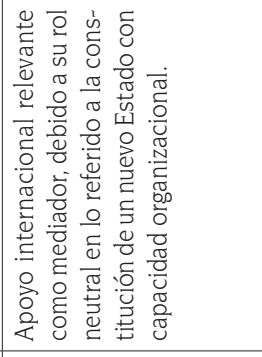 \\
\hline & & 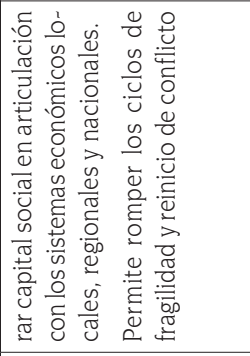 & 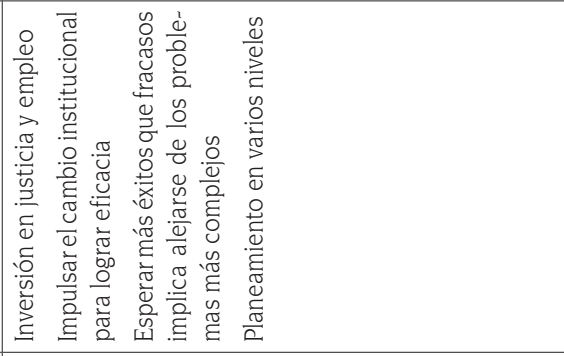 & & 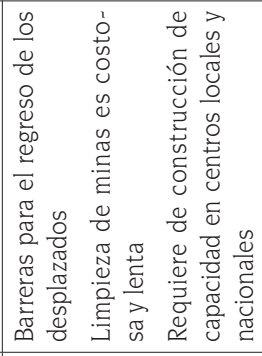 \\
\hline & & & 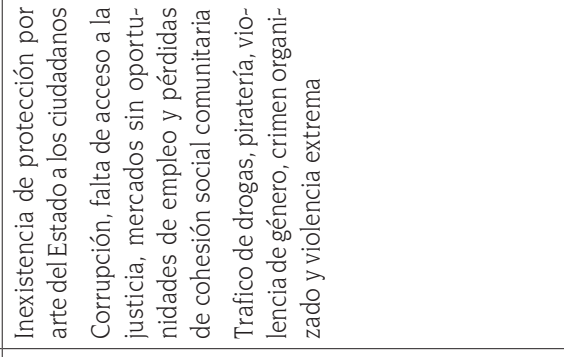 & & 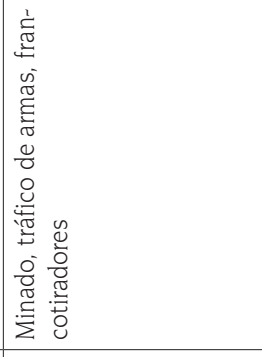 \\
\hline & & & 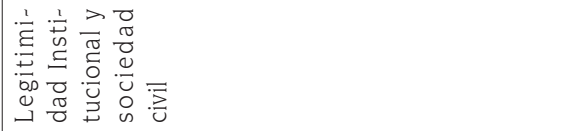 & & 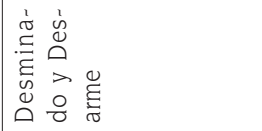 \\
\hline
\end{tabular}




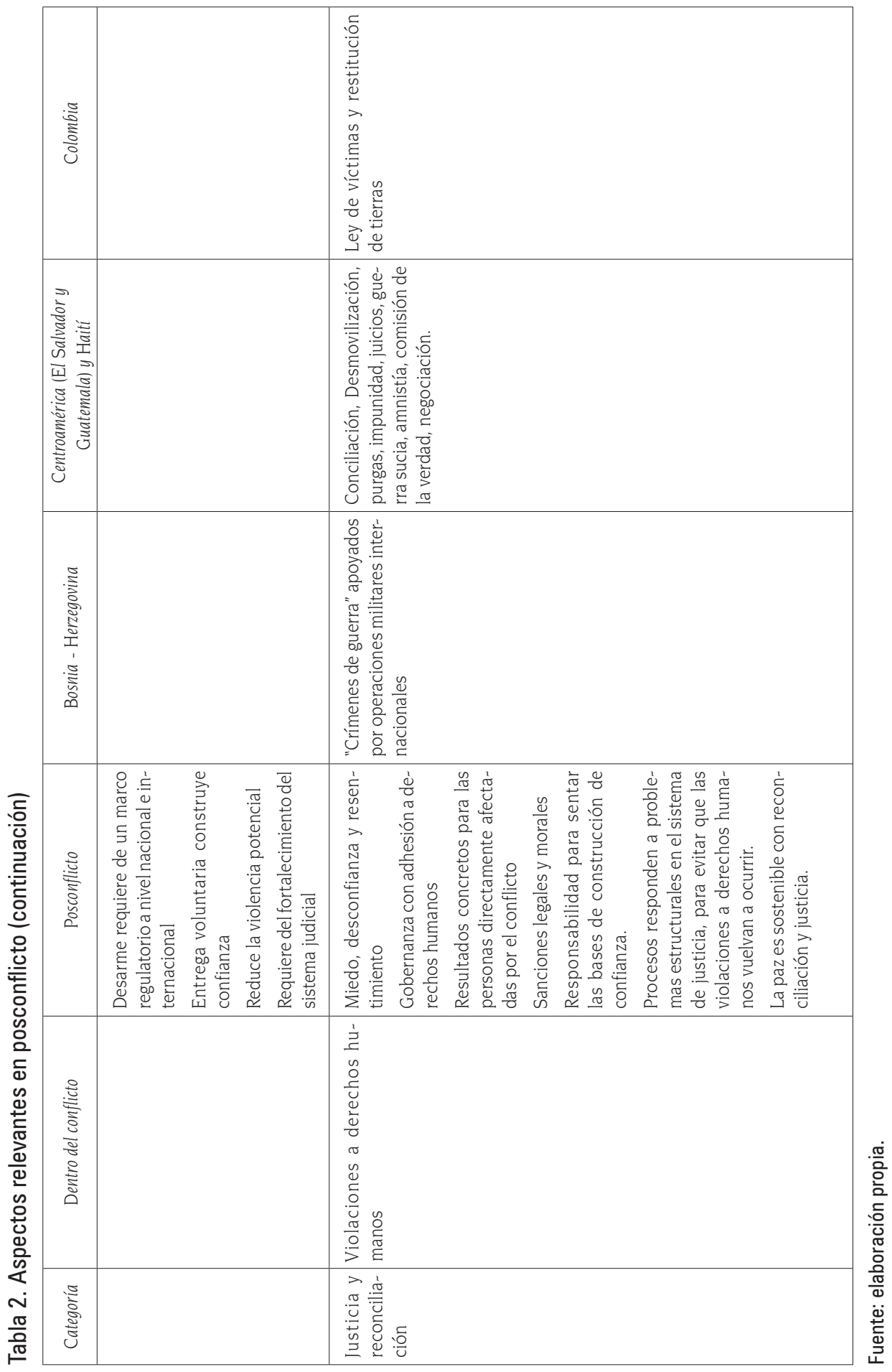




\subsection{Economía}

A continuación, se presenta un análisis del comportamiento de la inversión, la industria, la agricultura, los subsidios y transferencias, el gasto militar y el crecimiento anual del PIB para los países estudiados, utilizando la base de datos del Banco Mundial. La línea vertical de referencia en todos los gráficos indica el año promedio de la firma de los acuerdos de paz, fijado en 1997. En el gráfico 1 puede observarse la participación de la formación bruta de capital fijo promedio en el PIB, la cual se encuentra cerca del 20\% para el periodo 1990-2012. En promedio, se observa que la inversión como porcentaje del PIB aumenta levemente con los años en posconflicto, y la industria se mantiene con una participación similar a la registrada durante los años en conflicto; mientras que la participación de la agricultura disminuye progresivamente en los años de posconflicto.

Gráfico 1. Comportamiento de la inversión, 1990-2012

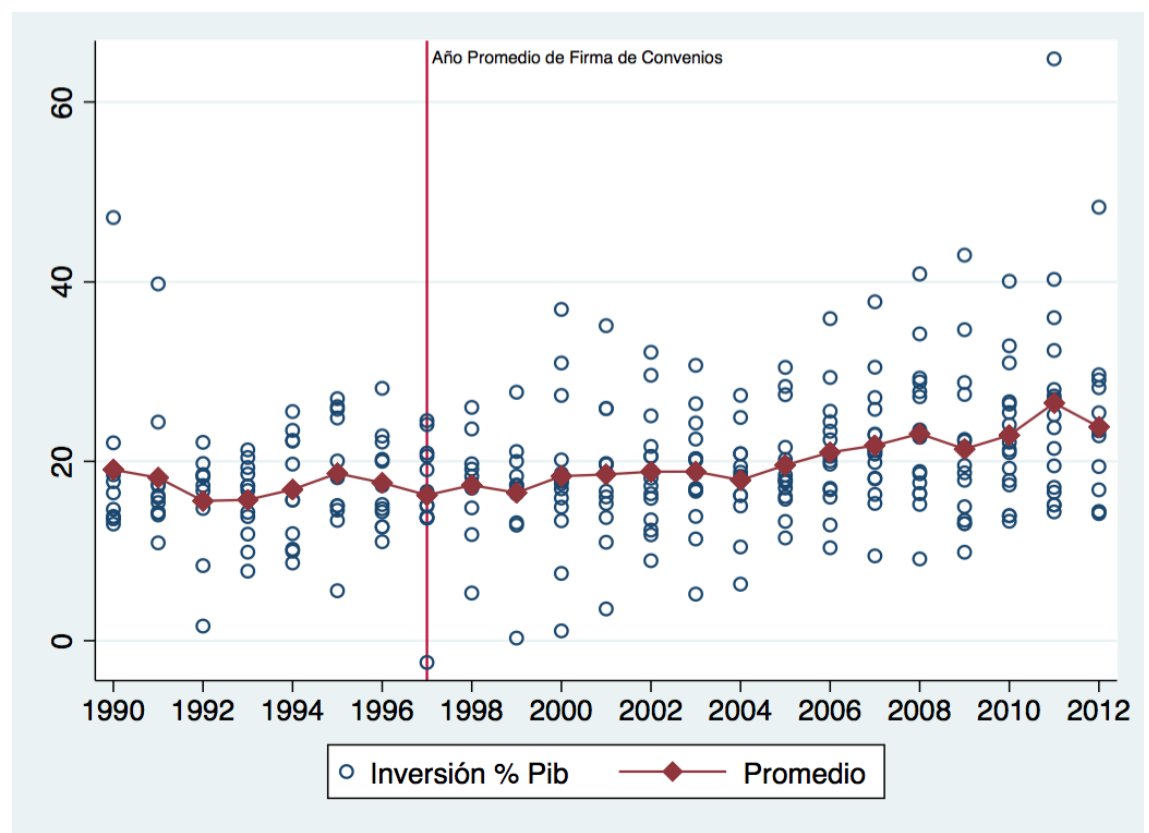

Fuente: elaboración propia con base en los indicadores del Banco Mundial 
Gráfico 2. Comportamiento de la industria, 1990-2012

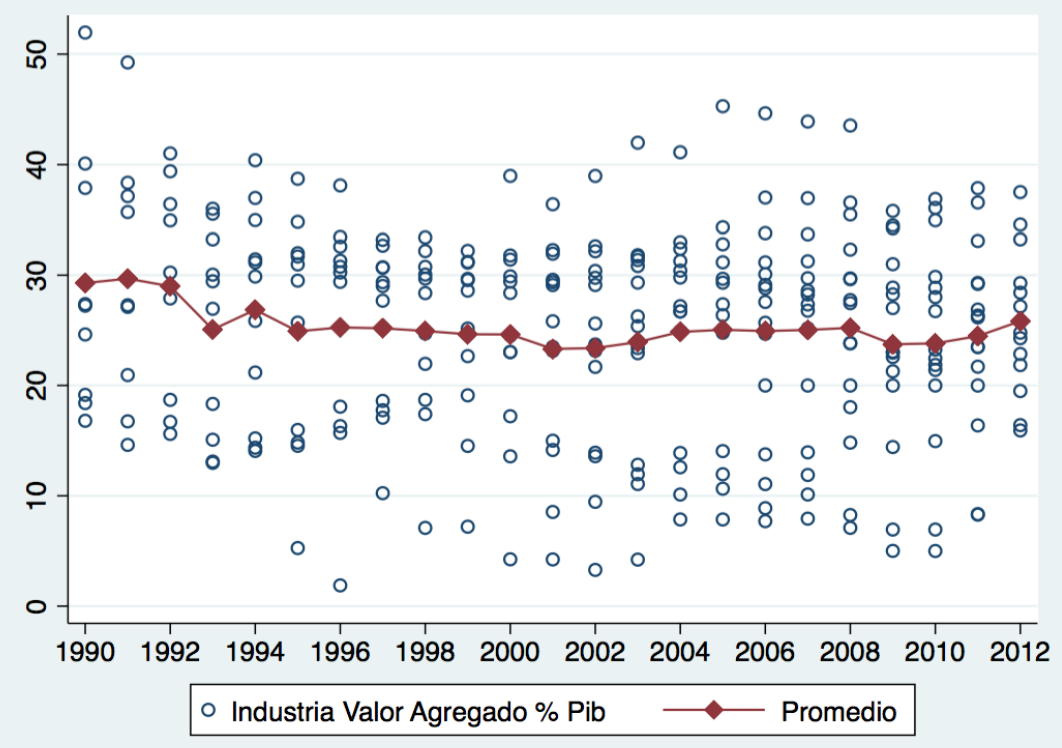

Fuente: elaboración propia con base en los indicadores del Banco Mundial

Gráfico 3. Comportamiento de la agricultura, 1990-2012

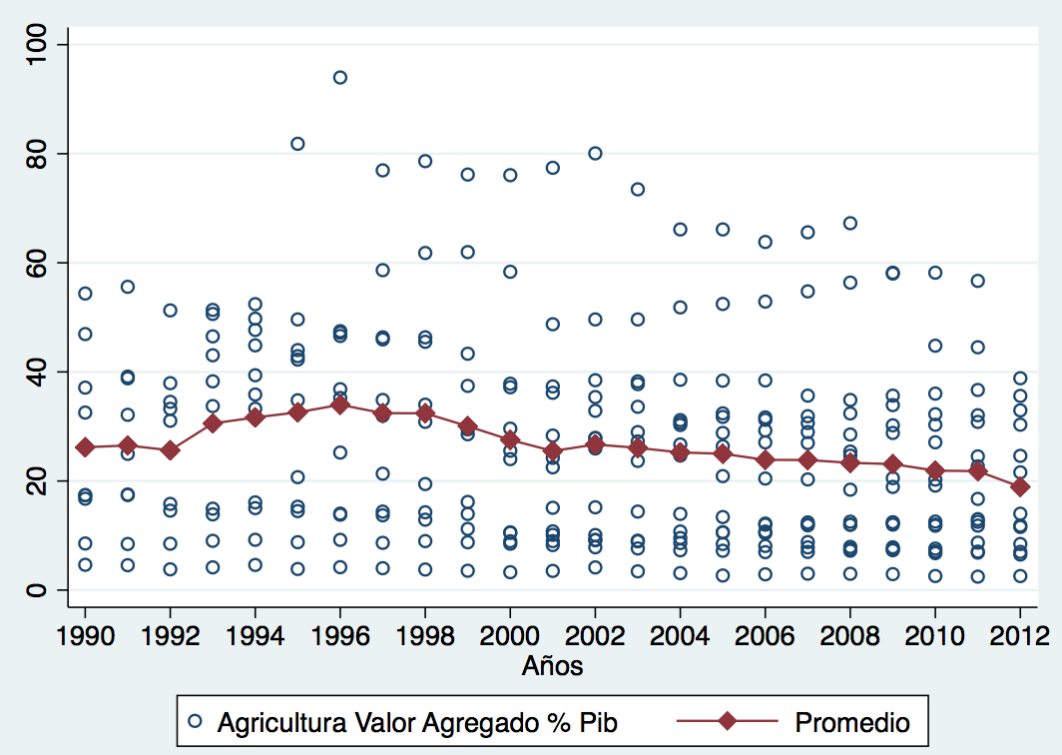

Fuente: elaboración propia con base en los indicadores del Banco Mundial 
Gráfico 4. Comportamiento de los subsidios y transferencias, 1990-2012

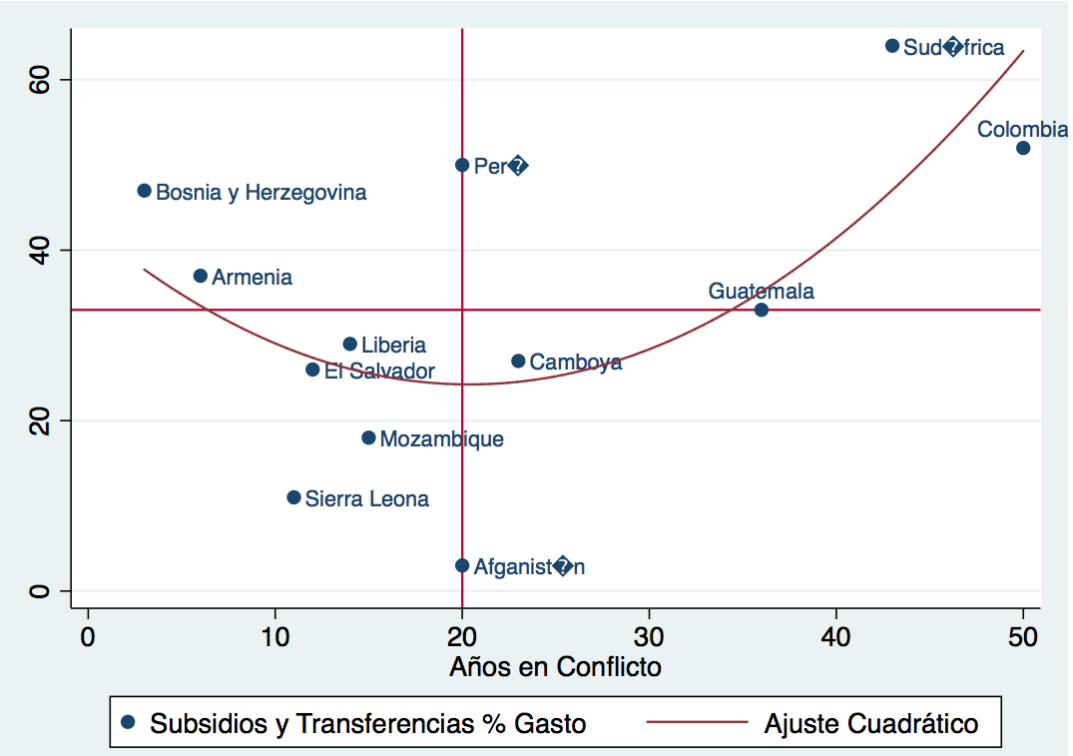

Fuente: elaboración propia con base en los indicadores del Banco Mundial

Gráfico 5. Comportamiento de la gasto militar, 1990-2012

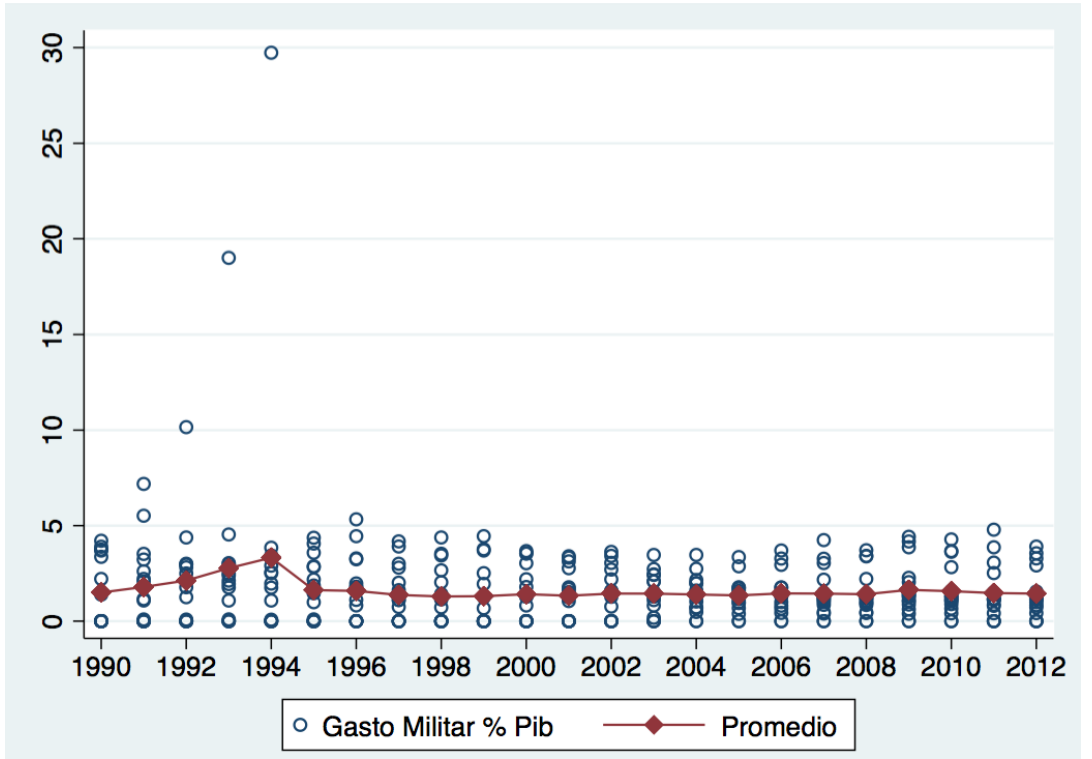

Fuente: elaboración de los autores con base en los indicadores del Banco Mundial 
Gráfico 6. Comportamiento del crecimiento anual del PIB, 1990-2012

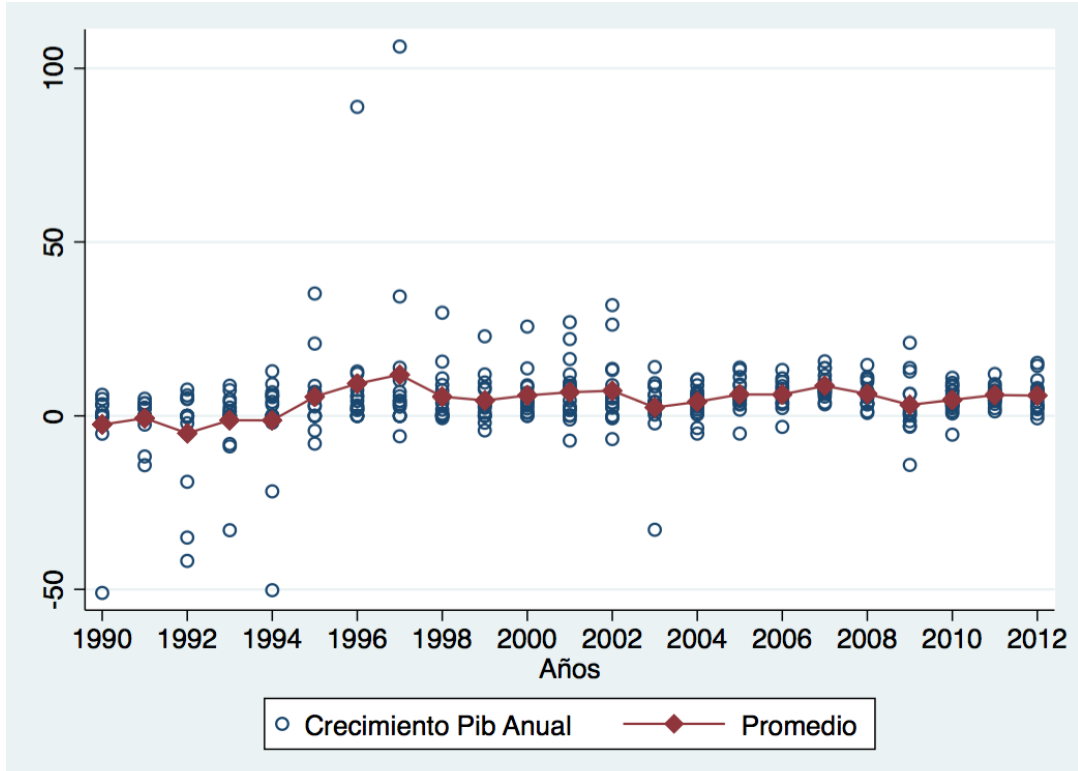

Fuente: elaboración propia con base en los indicadores del Banco Mundial

Gráfico 7. Promedio de años de escolaridad, 1990-2012

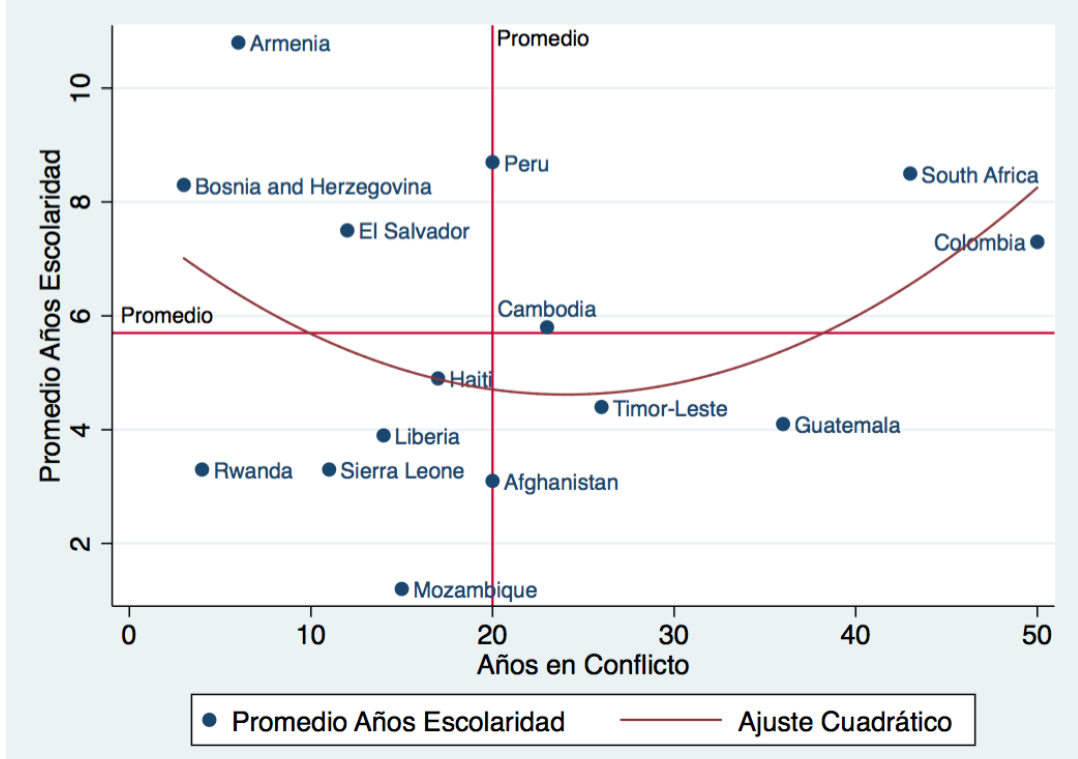

Fuente: elaboración propia con base en los indicadores del Banco Mundial 
Gráfico 8. Gasto en salud como proporción del PIB, 1990-2012

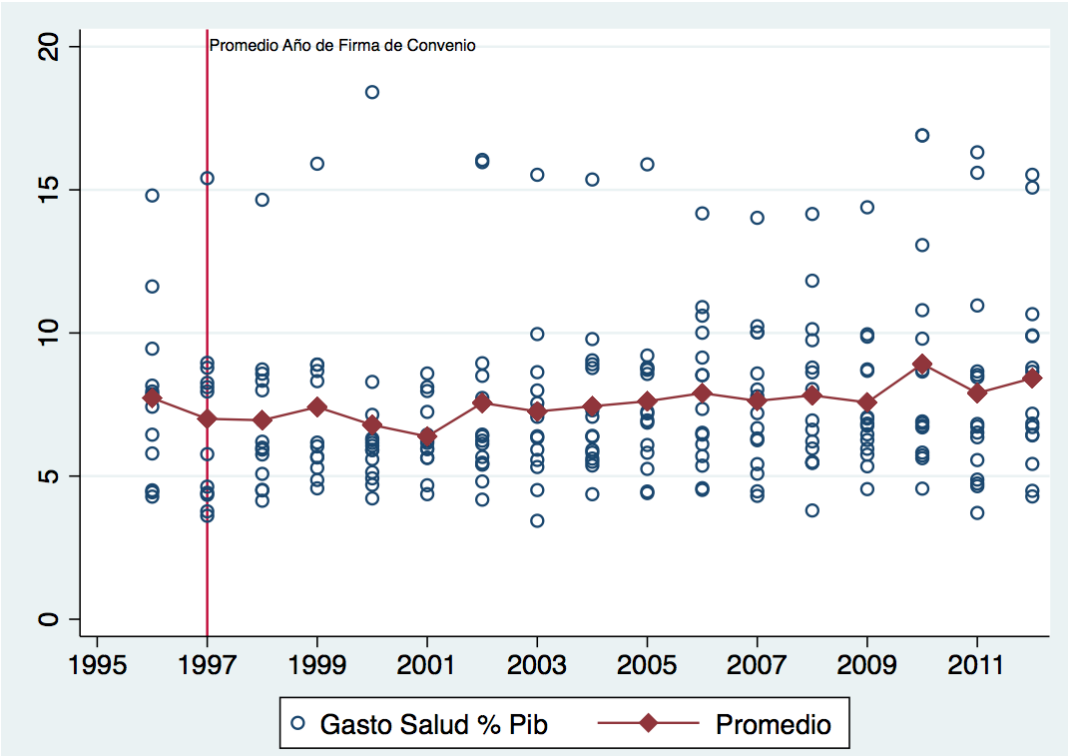

Fuente: elaboración propia con base en los indicadores del Banco Mundial

Gráfico 9. Gasto en educación como proporción del PIB, 1990-2012

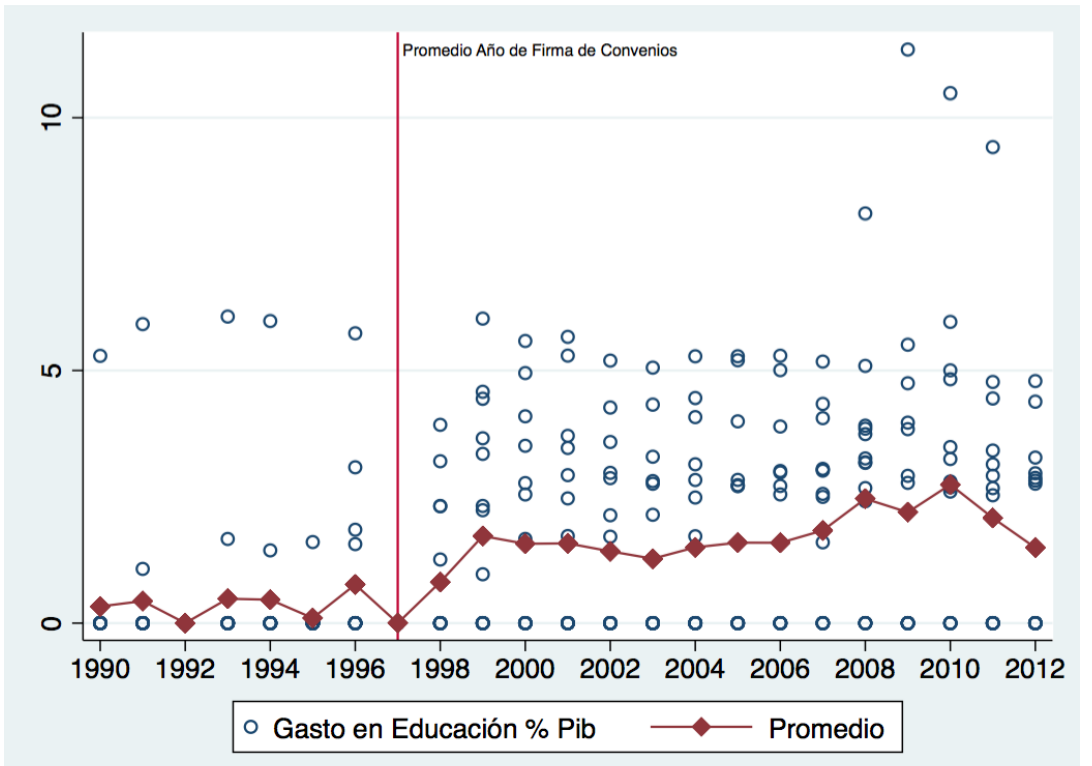

Fuente: elaboración de los autores con base en los indicadores del Banco Mundial 
William Orlando Prieto - Johanna Elizabeth Manrique

Gráfico 10. Gasto público en salud como proporción del PIB, 1990-2012

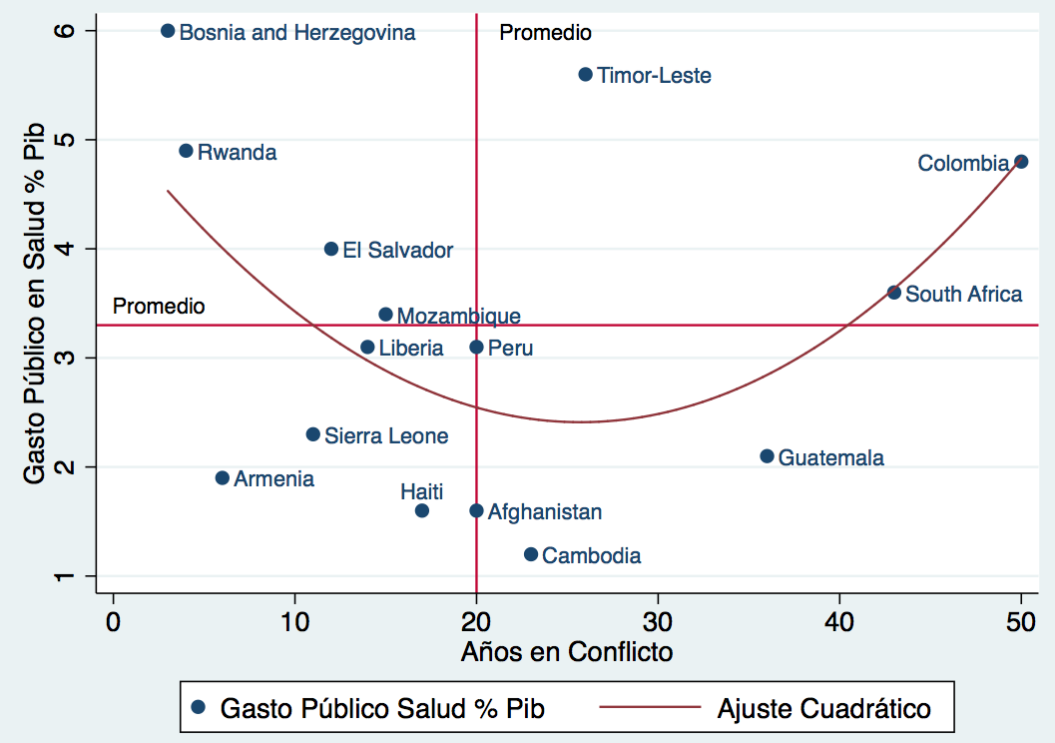

Fuente: elaboración propia con base en los indicadores del Banco Mundial

Gráfico 11. Tasa de mortalidad infantil, 1990-2012

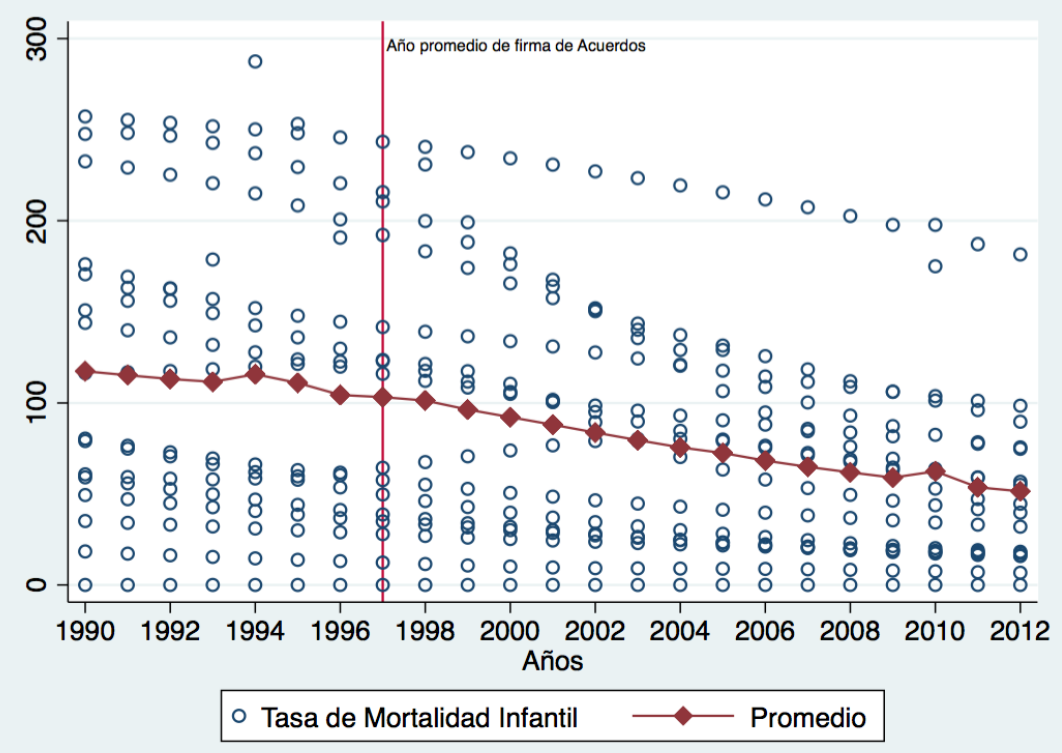

Fuente: elaboración propia con base en los indicadores del Banco Mundial 
Gráfico 12. Esperanza de vida, 1990-2012

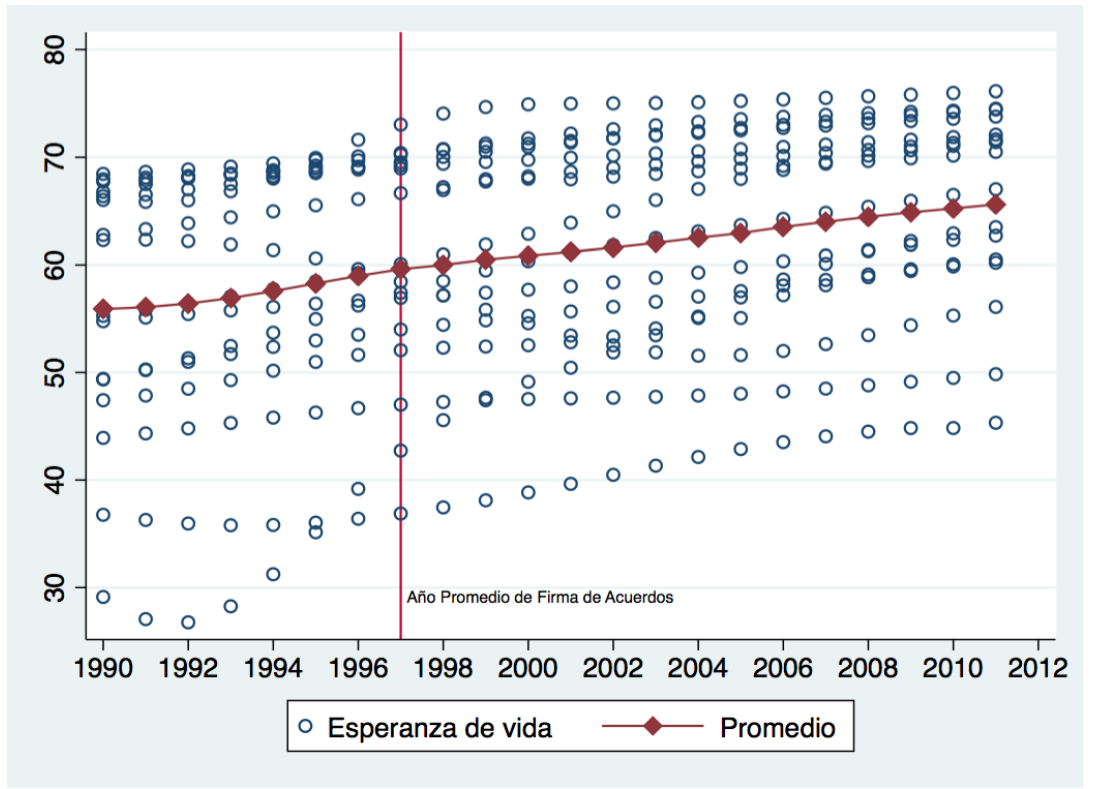

Fuente: elaboración propia con base en los indicadores del Banco Mundial

En cuanto al gasto militar, se observa una tendencia al incremento de acuerdo con el número de años en conflicto. Ello indica que economías como las de Colombia y Suráfrica -que ostentan los conflictos más antiguos- gastan mucho más en transferencias, subsidios y gasto militar frente a aquellas con conflictos de menos duración, como las de El Salvador, Liberia, Ruanda, Sierra Leona y Bosnia-Herzegovina (gráfico 5).

En el periodo 1990-2012, el crecimiento de la producción agregada anual fluctúa entre - 5 y 10\%, destacándose comportamientos extraordinarios en las economías de Liberia, Bosnia - Herzegovina y Ruanda (gráfico 6). Lo anterior parece confirmar a manera descriptiva la ocurrencia de un proceso de restauración de las economías de posconflicto que lleva tiempo, aun cuando los niveles de inversión permanecen por encima del 10\% en participación promedio del PIB.

\subsection{Capital humano}

La medición de capital humano se presenta a continuación a través de los siguientes indicadores: comportamiento de la escolaridad promedio; gasto en salud y en educación como proporción del PIB; tasa de mortalidad infantil; y esperanza de vida. El gasto promedio en salud (gráfico 8) se encuentra por encima del gasto promedio en educación (gráfico 9) para los países estudiados en el periodo 1990-2012. 
Aunque la proporción del gasto en salud es mayor, el crecimiento que refleja el cambio de pendiente es mayor para el promedio de gasto en educación después de 1997 (gráfico 9). Los incrementos en educación son sustanciales para las poblaciones de jóvenes, mujeres y adultos mayores, como lo indican los registros del Banco Mundial para la población de países incluidos en el análisis. Asimismo, la tasa de mortalidad infantil (gráfico 11) y la esperanza de vida (gráfico 12) presentan tendencias promedio consolidadas decrecientes y crecientes que favorecen la acumulación de capital humano en posconflicto.

Al contrastar el promedio de escolaridad y el gasto público en salud con los años de conflicto, se encuentran tendencias crecientes en los países que experimentan los conflictos más antiguos; tal es el caso de Suráfrica y Colombia, países que se encuentran por encima del promedio de escolaridad y gasto público en salud entre los casos analizados. Sin embargo, es necesario resaltar que los mismos países presentan las menores proporciones de población rural (tabla 1).

\subsection{Capital Social}

En este apartado se presentan como medidas de la acumulación de capital social el porcentaje de escaños ocupados por mujeres en los parlamentos nacionales (gráfico 13); el porcentaje de área selvática de los territorios nacionales (gráfico 14); los usuarios de internet (gráfico 15); los homicidios intencionales (gráfico 16); el índice de confianza en la gente, desarrollado por las Naciones Unidas (gráfico 17); y el índice de diversidad del lenguaje (gráfico 18), estimado por Alesina y Ferrara (2003).

Las tendencias promedio favorables en la institucionalidad en lo referente a la inclusión social, la conectividad y los homicidios, facilitan la acumulación de capital social en las sociedades en posconflicto. Algunas de las restricciones relevantes para la acumulación de capital social, tales como las dificultades geográficas para la comunicación que imponen los territorios selváticos y la diversidad de lenguajes, presentan tendencias creciente y decreciente, respectivamente.

Para el caso del indicador geográfico, la generación de capital social es mucho más difícil en países con los conflictos más antiguos y área selvática mayor al promedio, como corresponde a Colombia, Camboya y Timor Leste. La diversidad del lenguaje es mucho más frecuente en los conflictos de origen étnico como el de Bosnia - Herzegovina, y afecta la consecución de alternativas viables de sostenibilidad de la paz en países como Liberia, Mozambique y Sierra Leona. 
Gráfico 13. Porcentaje de escaños ocupados por mujeres en los parlamentos nacionales

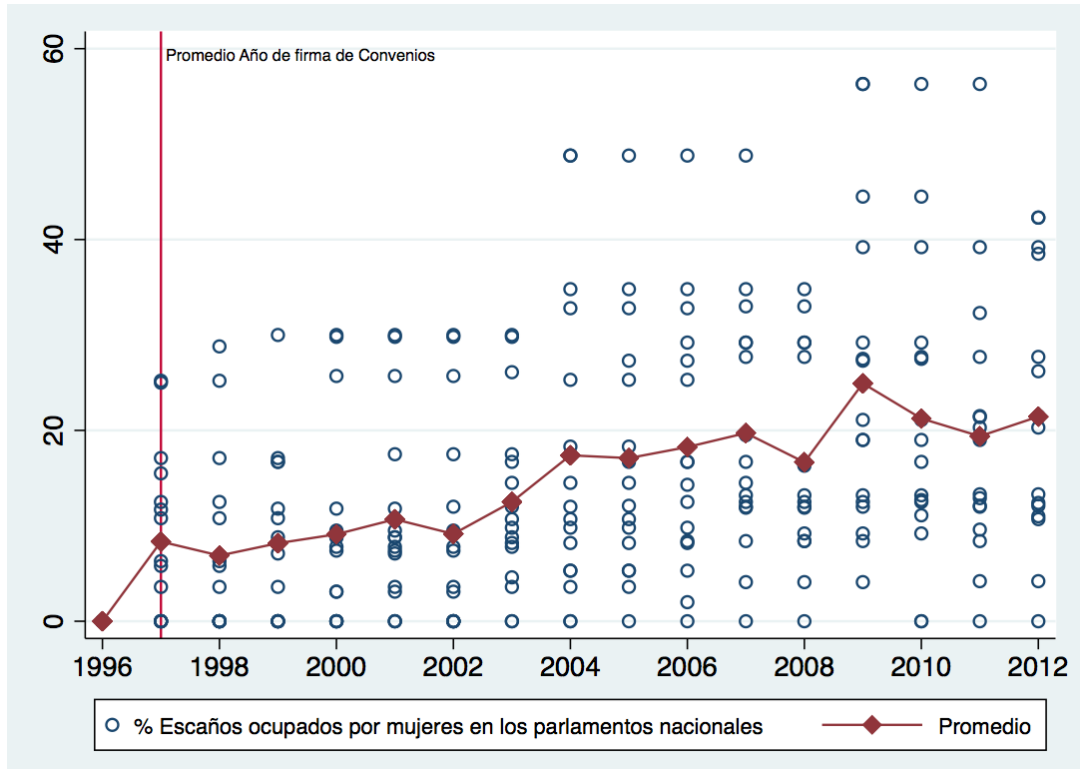

Fuente: elaboración propia con base en los indicadores del Banco Mundial

Gráfico 14. Porcentaje de área selvática de los territorios nacionales

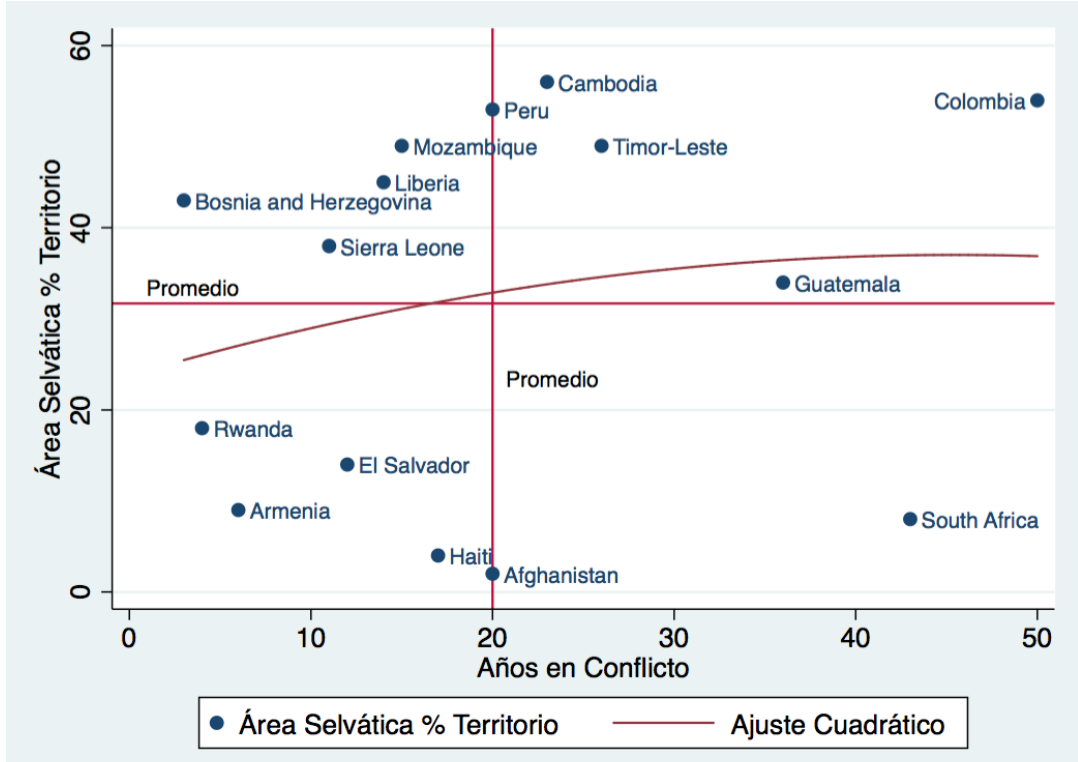

Fuente: elaboración propia con base en los indicadores del Banco Mundial 
Gráfico 15. Usuarios de internet

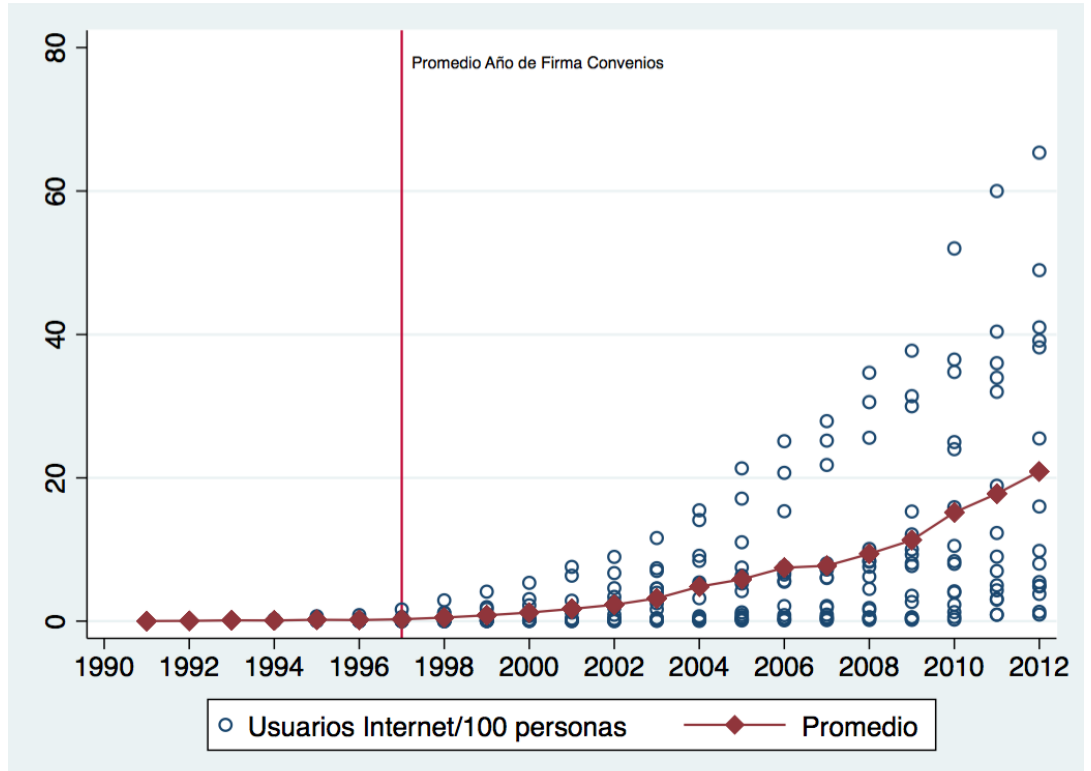

Fuente: elaboración propia con base en los indicadores del Banco Mundial

Gráfico 16. Homicidios intencionales

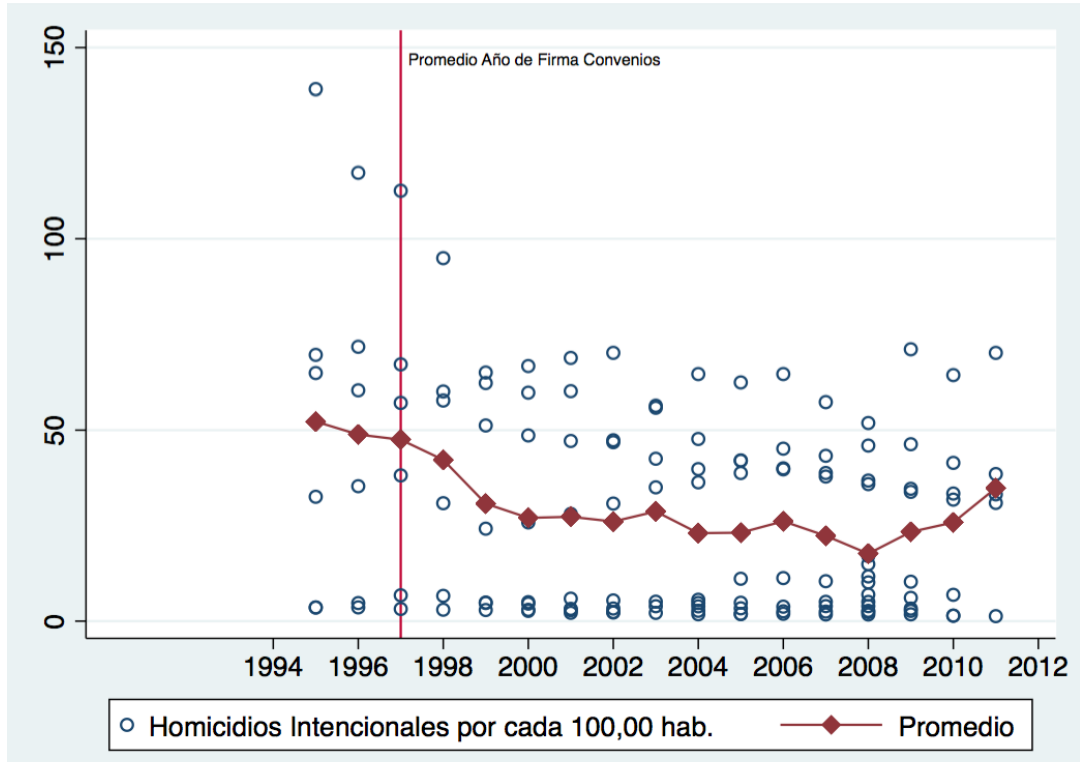

Fuente: elaboración propia con base en los indicadores del Banco Mundial 
Gráfico 17. Indice de confianza en la gente desarrollado por las Naciones Unidas

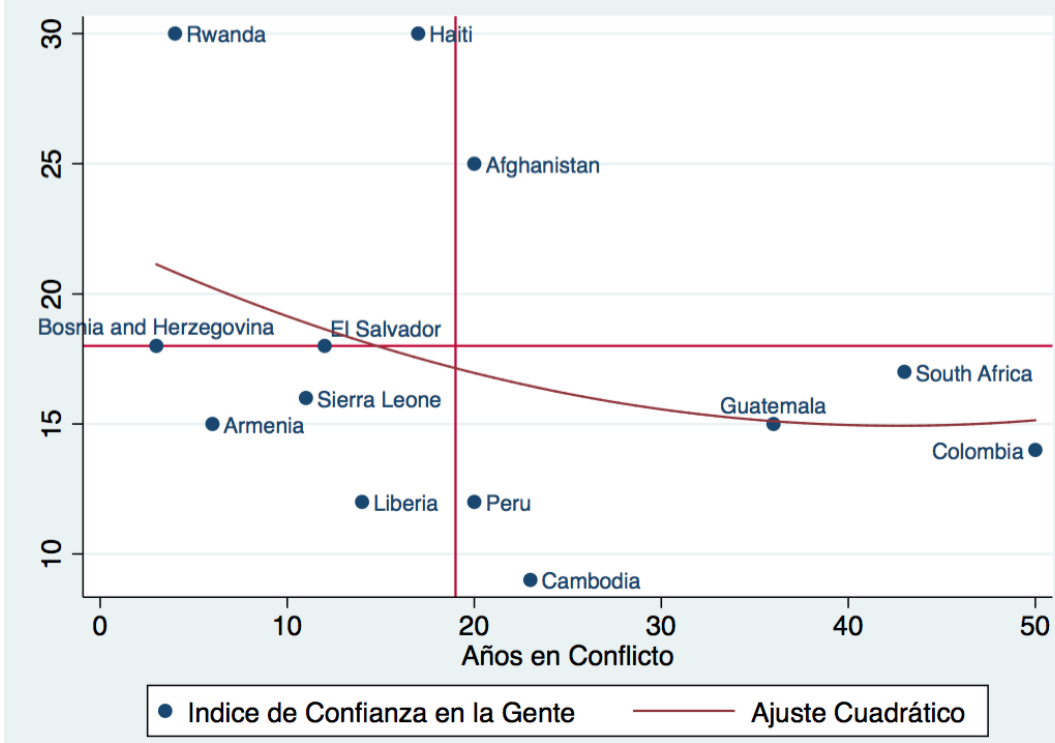

Fuente: elaboración propia con base en los indicadores del Banco Mundial

Gráfico 18. Índice de diversidad del lenguaje

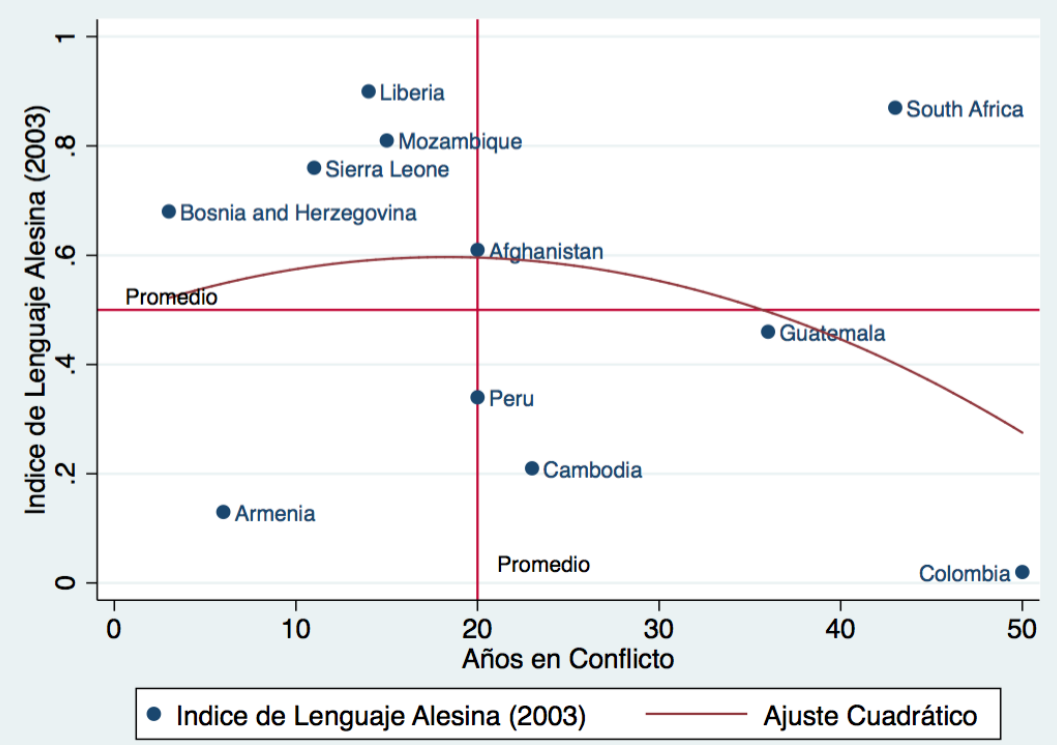

Fuente: estimación de Alesina y Ferrera (2003) 
Gráfico 19. Indice de percepción de la corrupción de Transparencia Internacional

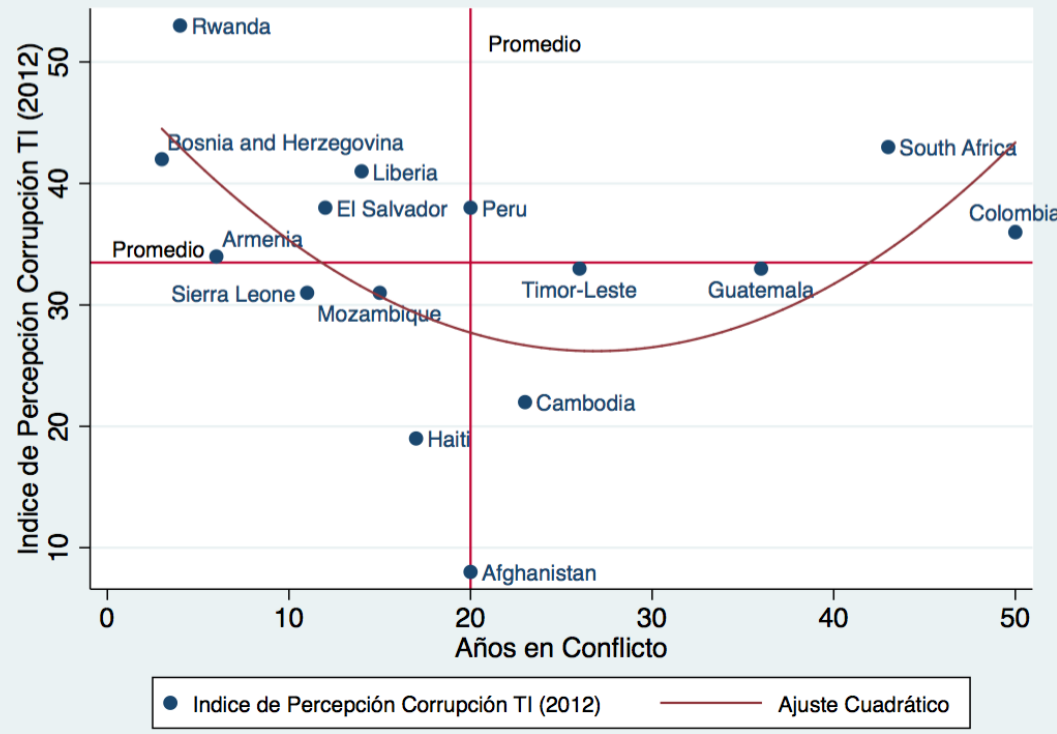

Fuente: elaboración propia con base en los indicadores del Banco Mundial

Gráfico 20. Índice de Confianza en el gobierno

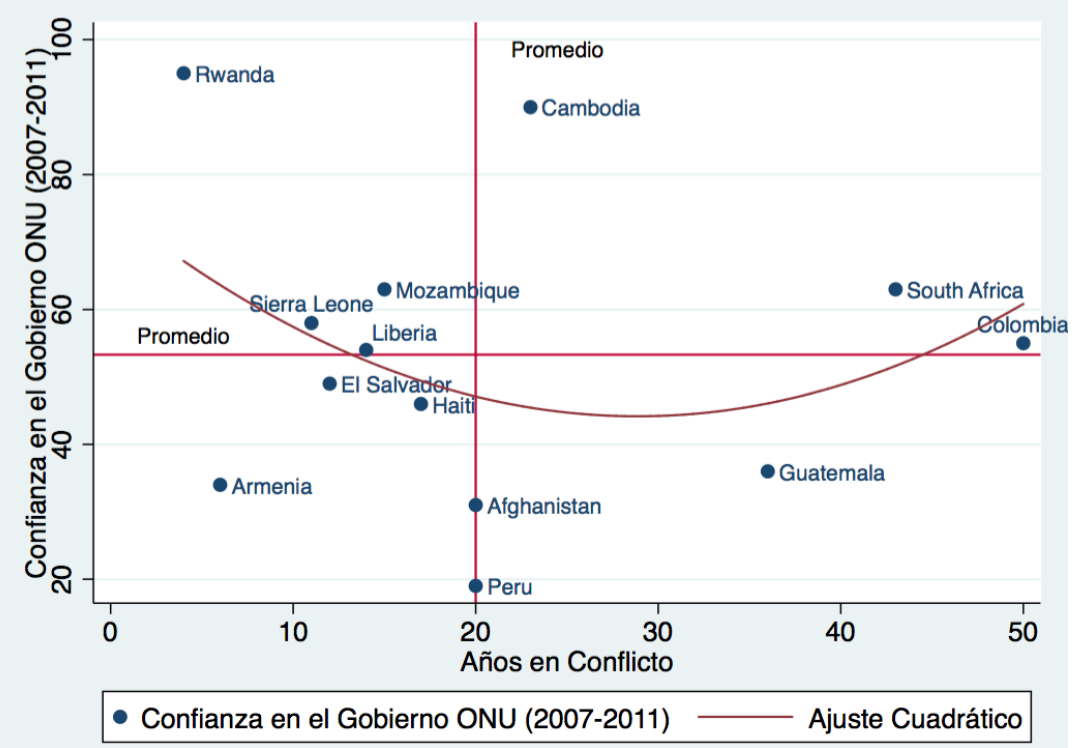

Fuente: elaboración propia con base en el Índice de Transparencia Internacional y la ONU (2012) 
Colombia presenta la menor diversidad de lenguaje, lo que alude a un conflicto de naturaleza político-económica, principalmente. De igual manera, la naturaleza del apartheid en Suráfrica especifica un alto nivel de diversidad cultural, en medio de un conflicto de segregación racial. Lo anterior parece indicar una relevancia mayor, en términos de los cambios identificados en la acumulación de capital social, en relación con la acumulación de capitales humano y físico en el posconflicto. Es decir, la reconstrucción de la confianza y la cohesión social en torno a una alternativa sostenible de paz es un aspecto clave durante los primeros años del posconflicto.

\subsection{INSTITUCIONES}

Debido a la importancia relativa de la generación de capital social, se describe el comportamiento de las instituciones públicas para identificar cambios de tendencia en los países, a través de dos índices: el de percepción de la corrupción de Transparencia Internacional (gráfico 19); y el de confianza en el gobierno (gráfico 20), desarrollado por la ONU.

Como se observa en los gráficos respectivos, ambos índices presentan una tendencia creciente con el número de años de conflicto. De esta manera, países como Colombia y Suráfrica presentan percepciones de corrupción y reducida confianza en los gobiernos, comparados con países que ostentan conflictos de menor data. En otras palabras, los años de duración del conflicto erosionan el capital social definido a partir de la credibilidad en las instituciones, lo cual causa una mayor percepción de corrupción y menor percepción de confianza.

\subsection{RESULTADOS EN DESARROLLO SOCIAL}

En cuanto a desarrollo social, se presentan los principales resultados en términos de la distribución del ingreso, medida a través del coeficiente Gini; y la pobreza, medida a través del porcentaje de población en pobreza multidimensional, los índices de desarrollo humano (IDH) y desigualdad de género, y la tasa de desempleo.

Como se observa en el gráfico 21, las disminuciones en el coeficiente Gini ocasionadas por el crecimiento económico son mucho más difíciles de alcanzar en los países con conflictos más antiguos. Naciones como Colombia, Suráfrica, Guatemala, Ruanda, Perú y Mozambique, que se encuentran por encima del ajuste cuadrático, tienden a presentar concentraciones más altas del ingreso frente a Afganistán, Armenia, Camboya, Timor Leste y Liberia, que se encuentran por debajo de dicho ajuste.

Lo anterior se confirma en el gráfico 24, que describe una tendencia creciente de la concentración del ingreso en el número de años de conflicto; allí sobresalen 
Colombia y Suráfrica con las mayores concentraciones del ingreso y los conflictos más antiguos. Por otro lado, las mejoras en el porcentaje de población en pobreza multidimensional (gráfico 22) de países con conflictos más antiguos, como Colombia, Suráfrica y Perú, parecen estar directamente vinculadas a una menor participación de población rural (tabla 1), correspondiente al 24\%, 38\% y 22\%, respectivamente, en relación con los demás países. Del mismo modo, los países con mayor población rural registran menores logros en pobreza: así entonces, Ruanda, Mozambique y Sierra Leona ostentan una participación de población rural de 81\%, $69 \%$ y $60 \%$, respectivamente.

El índice de desigualdad de género (gráfico 26) y la tasa de desempleo (gráfico 23) presentan comportamientos opuestos. Además, los países con menor número de años en conflicto reducen la tasa de desempleo con mayor facilidad que los países cuya situación es opuesta. De igual modo, la desigualdad de género es mucho menor en países con menor número de años en conflicto que en los que ostentan una situación opuesta.

Gráfico 21. Comparación de coeficiente Gini por países, de acuerdo con el crecimiento anual del PIB

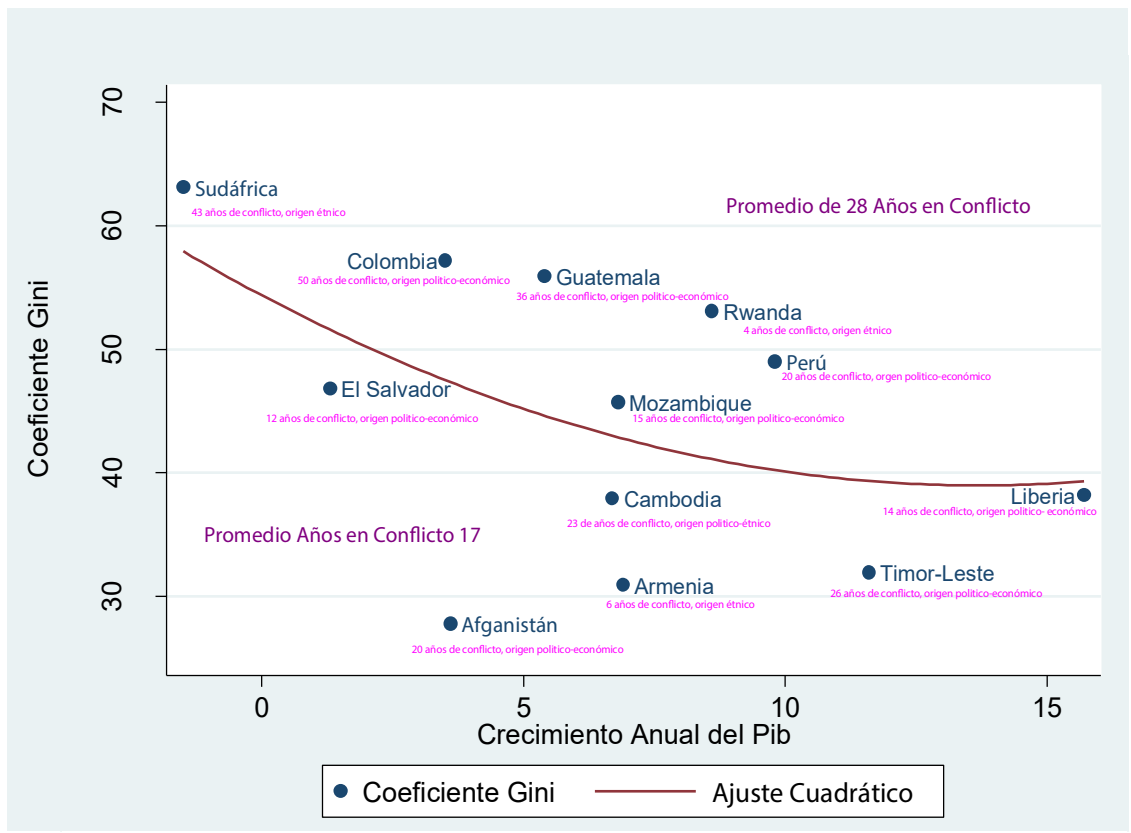

Fuente: elaboración propia con datos de la ONU (2012) 
Grático 22. Comparación de porcentaje de población en pobreza multidimensional por países, de acuerdo con el crecimiento anual del PIB

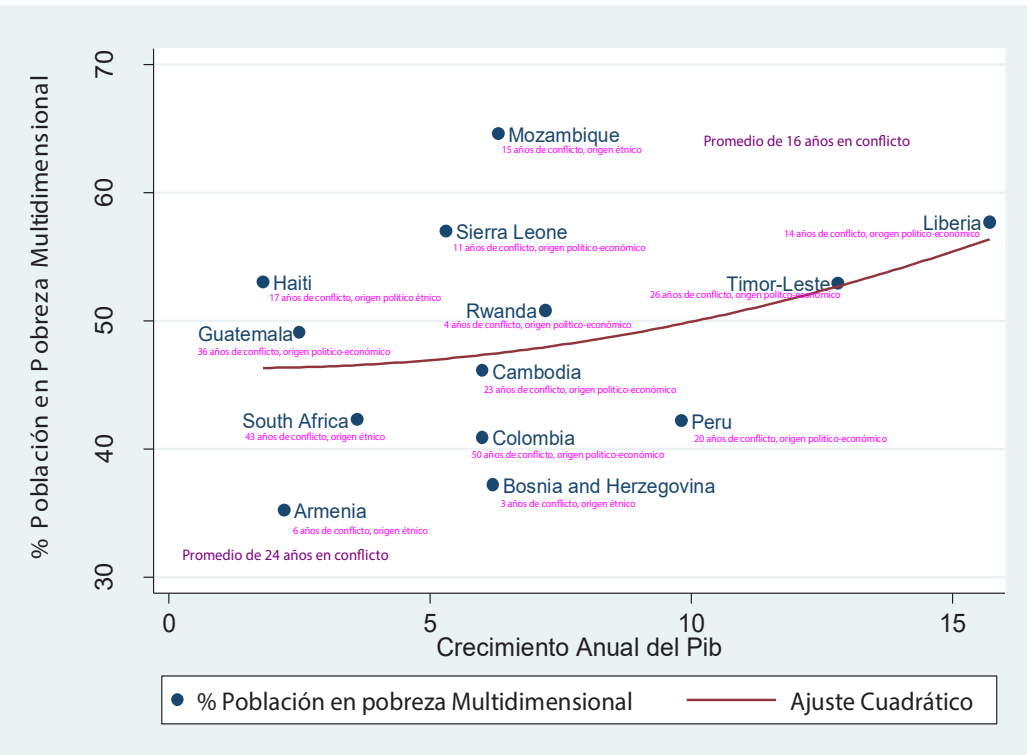

Fuente: elaboración propia con datos de la ONU (2012)

Gráfico 23. Comparación de la tasa de desempleo por países, de acuerdo con el número de años de conflicto

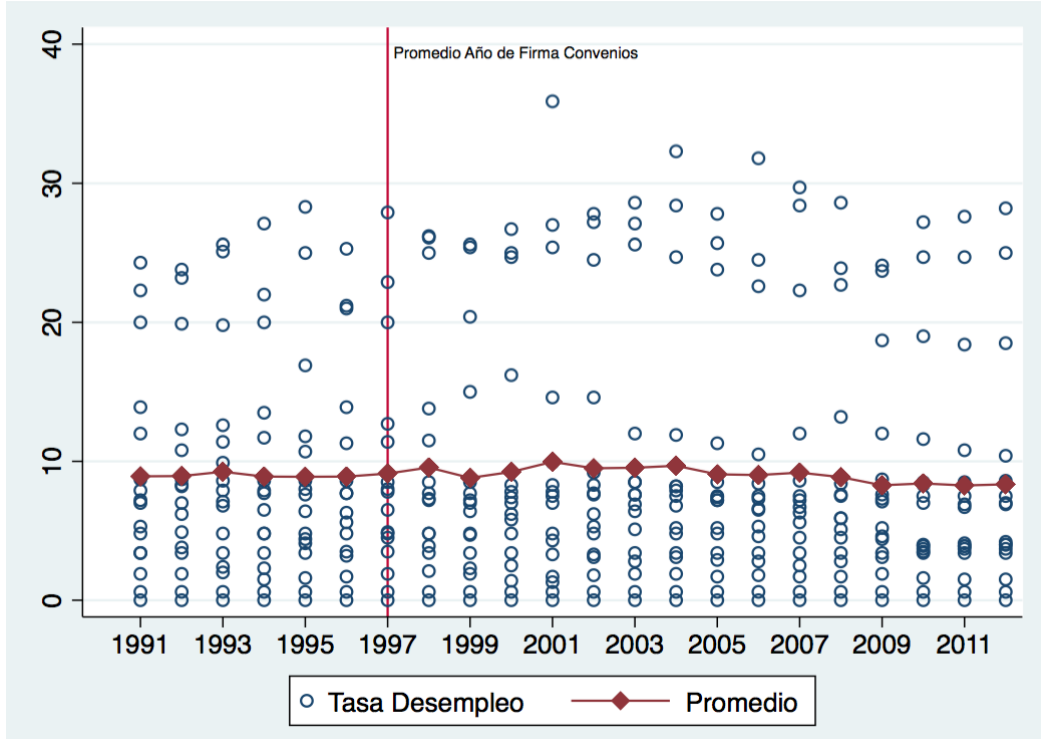

Fuente: elaboración propia con datos de la ONU (2012) 
Gráfico 24. Comparación del coeficiente Gini por países, de acuerdo con el número de años de conflicto

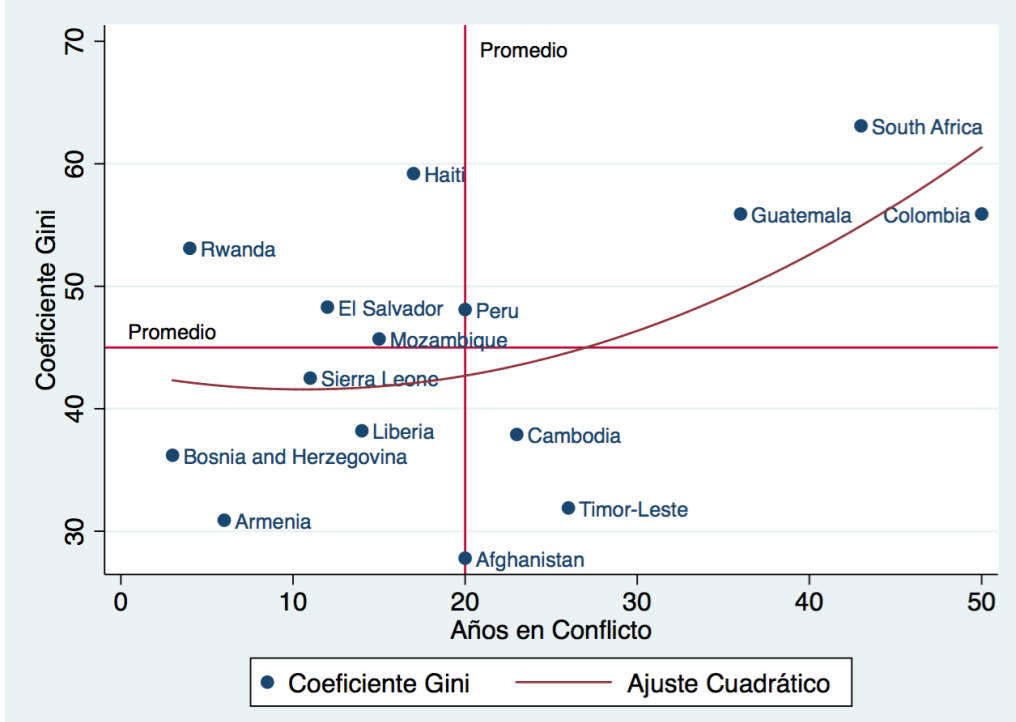

Fuente: elaboración propia con datos de la ONU (2012)

Gráfico 25. Comparación de IDH por países

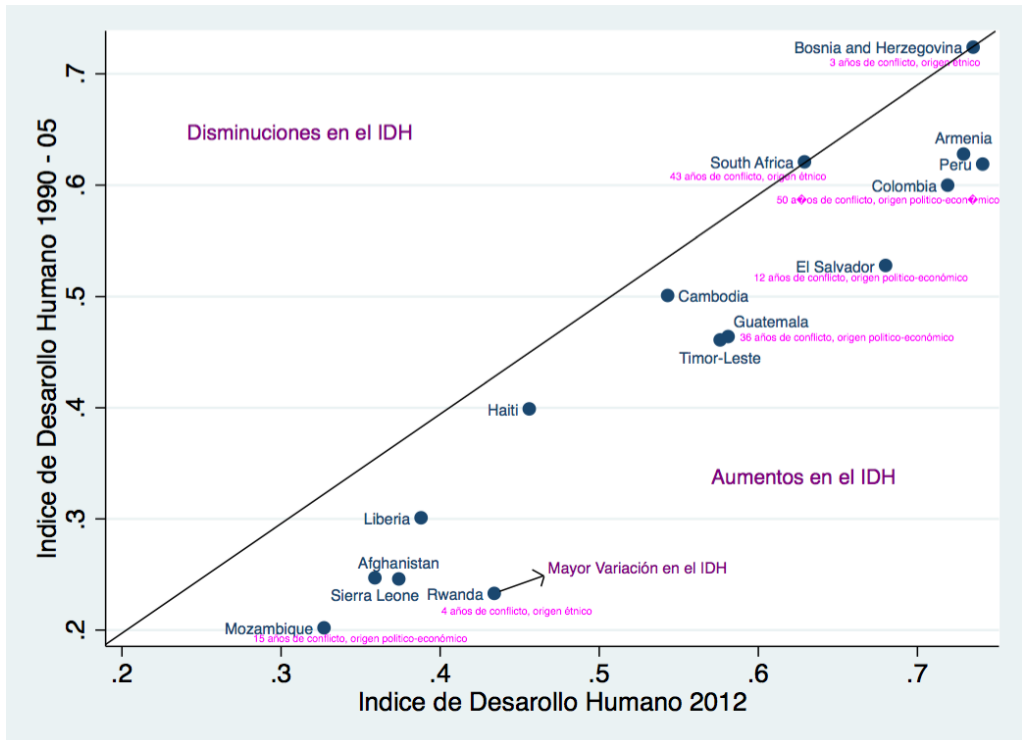

Fuente: elaboración propia con datos de la ONU (2012) 
Gráfico 26. Comparación del Índice de desigualdad de género por países de acuerdo con número de años de conflicto

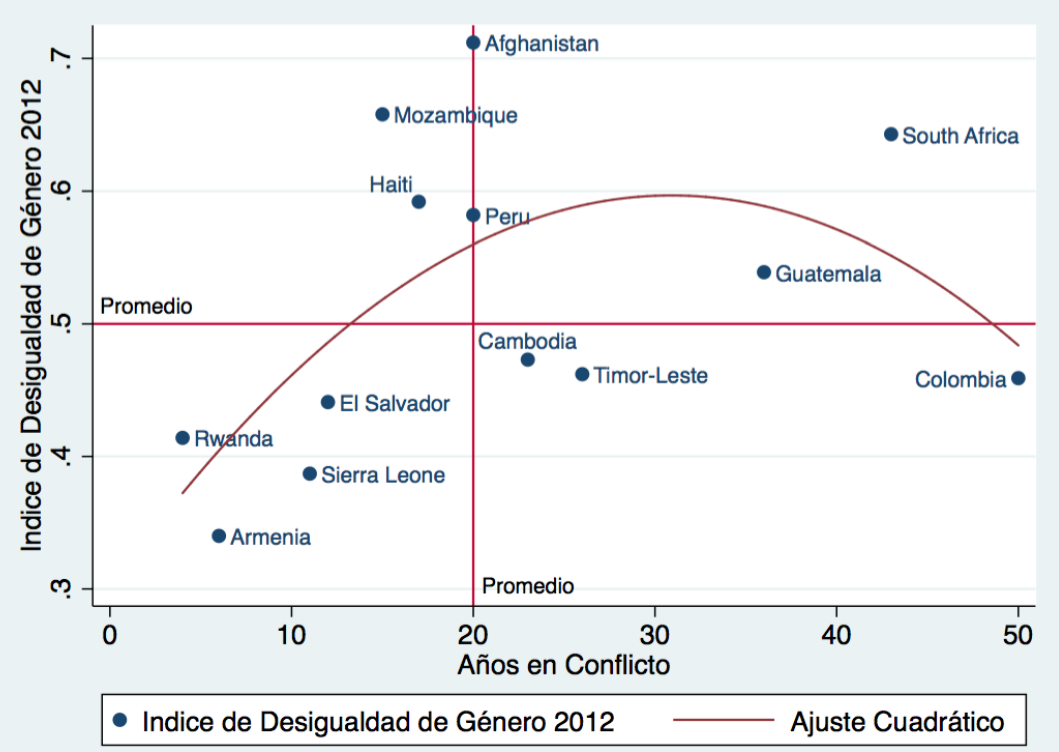

Fuente: elaboración propia con datos de la ONU (2012)

En particular, los países que han experimentado misiones de la ONU, tales como Mozambique y Ruanda ${ }^{1}$, con las cuales se han implementado mecanismos de reconstrucción sobre una base comunitaria en articulación con sistemas locales, regionales y nacionales, experimentan mejoras sustanciales en la ocupación y el desarrollo humano. En cambio, países como Suráfrica y Colombia presentan conflictos raciales y político-económicos que han dificultado la implementación de planeación local de arriba hacia abajo, dada la complejidad de sus conflictos armados en términos de presencia de actores desestabilizadores y garantías de seguridad.

Los resultados de desarrollo social plantean dos descripciones preliminares. Primero, las experiencias de los países africanos con planeación de base comunitaria han sido exitosas en la medida en que han logrado mejoras en los índices de desarrollo humano: de hecho, Ruanda presenta la mayor variación en el IDH al comparar las décadas de 1990 y 2000 (gráfico 25). Y segundo, los países con con-

A 1990, países como Bosnia - Herzegovina, Timor Leste, Camboya y Liberia no registran IDH, por lo cual se tomó un promedio de 1990 hasta 2005 para completar la serie comparativa con 2012. En la variación del promedio de 1990 a 2005, Timor Leste y Ruanda presentan las variaciones positivas más altas. El análisis destaca el desempeño de Ruanda porque presenta información del IDH en 1980, 1990, 2000 y 2005, mientras que Timor Leste solo registra datos para 2000 y 2005. 
flictos más antiguos parecen haber alcanzado un estado estacionario, en tanto la consolidación de un sistema de violencia en las zonas rurales no les permite lograr resultados tangibles en desarrollo humano. En tal sentido, los niveles de captura regulatoria del gobierno, así como la disminución aparente de los homicidios, refieren a una disminución de la tensión política por la disputa del poder regional, en convivencia con formas alternativas de conflicto que se ven representadas en mercados del crimen paralelos a los esfuerzos de reconstrucción social en el posconflicto. Lo anterior bloquea los avances en desarrollo social, medidos en una menor concentración del ingreso y niveles más bajos de pobreza.

\section{CONCLUSIONES}

El documento presenta evidencia para contrastar de manera descriptiva las experiencias de política pública en posconflicto para 16 países. Dos conclusiones sobresalen: por un lado, la planeación de base comunitaria es relevante durante el período de reconstrucción social, particularmente en los estudios de caso en África; y por otro, como se expresó pocas líneas atrás, los países con conflictos más antiguos -y de modo particular, los de América Latina- parecen haber alcanzado una situación estacionaria, con la consolidación de un sistema de violencia en las zonas rurales.

Lo anterior permite sugerir la existencia de ciclos de violencia, los cuales se retroalimentan por la debilidad institucional y la falta de capacidad local, así como por la reducida inversión en seguridad y en capital humano, lo cual disminuye el costo de oportunidad de participar en actividades ilegales y criminales. No obstante, en lo que atañe al objetivo principal de este estudio, se podría decir que en Colombia no es factible el resurgimiento del conflicto armado durante la fase de posconflicto, siempre y cuando se realicen la respectivas inversiones en las dimensiones abordadas y sus variables: economía, capital humano, capital social, instituciones y desarrollo social.

Las prioridades para neutralizar los efectos de retroalimentación de la violencia, habida cuenta de que la reactivación del sistema económico requiere tiempo para establecerse, están en una acumulación de capital social relativamente mayor en el corto plazo que la acumulación de capitales físico y humano, en modelos de desarrollo económico alternativos de base democrática y participativa.

Vista en prospectiva, una de las principales contribuciones de los acuerdos de paz es la separación de la violencia del conflicto social. En el caso particular de Colombia, la firma del acuerdo de paz separa de manera tajante la violencia utilizada para reivindicar derechos sociales, de aquella empleada como mecanismo de control social para expropiar recursos económicos de la nación (minería ilegal y 
contrabando) y las víctimas del conflicto (tierras, y activos de propiedad individual). Lo anterior permite repensar el modelo de desarrollo necesario para responder al conflicto social, mientras se establecen de manera conjunta las condiciones de seguridad para evitar el resurgimiento de ciclos de violencia fundados en un interés económico o político definido.

El comportamiento del mercado de trabajo en ausencia de una demanda laboral capaz de absorber los incrementos en la oferta laboral sin aumentar la informalidad y los mercados del crimen, requiere la acumulación de capitales humano, institucional y físico, así como de modelos alternativos como los de economía solidaria y economías mixtas, en un ejercicio democrático y participativo. Según los estudios de caso revisados, las estrategias de este tipo han permitido alcanzar logros relevantes en la sostenibilidad de los acuerdos de paz: estos se ven reflejados en una menor tensión, tanto en la concentración de recursos económicos como en la presencia de organizaciones comunitarias en los distintos eslabones de las cadenas de valor en el territorio, particularmente en las áreas rurales más afectadas por el conflicto armado.

El presente estudio muestra evidencia descriptiva acerca de las características más relevantes de la política económica para un grupo de países en posconflicto. En tal sentido, se refleja en el trabajo un ajuste de las variables de interés a nivel agregado. Una extensión necesaria concierne a la discusión microeconómica en ámbitos sociales clave para la sostenibilidad de un acuerdo de paz, tales como la educación, el sistema de seguridad social y salud, y la inserción laboral. Para tal efecto, será necesario realizar una comparación de programas o proyectos representativos para las sociedades en posconflicto, a partir de la cual sea posible complementar las conclusiones del estudio mostrado aquí.

\section{REFERENCIAS}

Ali, Abdel-Gadir (2009). A Policy Framework for Transiting from Postconflict Recovery to Sustainable Development in Sub-Saharan Africa. En: Journal of African Economies, Vol. 18, n. $^{\circ}$, p. $12-52$.

AIF (2007). Afganistán: Apoyo para la construcción del Estado y el desarrollo. En: La AIF en acción, 12p.

Akresh, R.; Verwim, P. y Bundervoet, T. (2011). Civil War, Crop Failure, and Child Stunting in Rwanda. En: Economic Development and Cultural Change, Vol. 59, n. ${ }^{\circ} 4$, p. 777-810.

Alesina, A. y Ferrara, E. L. (2005). En: Ethnic Diversity and Economic Performance. En: Journal of Economic Literature, Vol, $\overline{43}$, n. 3 3, p. 762-800.

Amman, J. y O'Donnell, J. (2011). The Sierra Leona Teachers Union: labor in a Post Conflict Society. Working USA. En: The Journal of Labor and Society, Vol. 14, n..$^{\circ}$, p. 57-71. 
Ansoms, A. (2005). Resurrection after Civil War and Genocide: Growth, Poverty and Inequality in Post-Conflict Rwanda. En: The European Journal of Development Research, Vol.17, n. ${ }^{\circ}$ 3, p. 495-508.

Banco Mundial (2005). Implementation Completion Report (grtd-h0090 tf-51247 tf-51429) on a Grant in the Amount of sdr 33.7 Million (us \$42 million equivalent) to the Islamic Republic of Afghanistan for the Emergency Community Empowerment and Public Works Project. World Bank Publications, 35p.

Banco Mundial (2010). Implementation Completion and Results Report (ida-35380 ida-35381) on Credits in the Amount of sdr 11.8 million (us\$ 15.0 million equivalent) and sdr 3.4 million (us\$ 5.0 million equivalent) to Bosnia and Herzegovina for a Community Development Project and Additional Financing. Banco Mundial, 43p.

Colleta, N.; Kostner, M.; Cleves, P. y Mendelson, J. (2000). Toward an Architecture for Sustainable Peace and Development: Lessons from the World Bank's Experience, p. 159-193. En: A. Solimano (Ed.), Colombia: Essays on Conflict, Peace, and Development. Washington, D.C.: Banco Mundial, 214p.

Collier, P. (2009). Post-conflict Recovery: How Should Strategies be Distinctive? En: Journal of African Economies, Vol. 18, Supplement 1, p. i99-i131.

Collier P.; Hoeffler, A. y Soderbom M. (2004). On the Duration of Civil War. En: Journal of Peace Research, Vol. 41, n. ${ }^{\circ}$ 3, p. 253-273.

Collier O.; Hoeffler A. y Rohner D. (2008). Beyond Greed and Grievance: Feasibility and civil war. En: Oxford Economic Papers, Vol. 61, n. 1, p. 1-27.

Dursun-Ozkanca, O. (2009). Rebuilding Kosovo: Cooperation or Competition between the EU and NATO? En: XI Conferencia Internacional Bianual EUSA. Los Ángeles: Elizabethtown College, Department of Political Science, 40p.

Erica, J. (2010). Ruptures, Rights, and Repair: The Political Economy of Trauma in Haiti. En: Social Science \& Medicine Vol. 70, n. ${ }^{\circ}$, p. 106-113.

Englebert, P., y Tull, D. M. (2008). Postconflict Reconstruction in Africa: Flawed Ideas about Failed States. En: International Security, Vol. 32, n. ${ }^{\circ}$ 4, p. 106-139.

Eriksson, J. R.; Kreimer, A. y Arnold, M. (2000). El Salvador: Post-Conflict Reconstruction, Country Case Study Series. Washington: Banco Mundial, 73p.

Finnoff, K. (2012). Intimate Partner Violence, Female Employment, and Male Backlash in Rwanda. En: The Economics of Peace and Security Journal, Vol. 7, n. ${ }^{2}$ 2, p. 14-24.

Fred-Mensah, B. (2004). Social Capital Building as Capacity for Post Conflict Development: The UNDP in Mozambique and Rwanda. En: Global Governance, Vol. 10, n. ${ }^{\circ}$ 4, p. 437-457.

Garstka, G. J. (2010). Post-conflict Urban Planning: The Regularization Process of an Informal Neighborhood in Kosova/o. En: Habitat International, Vol. 34, n. ${ }^{\circ}$ 1, p. 86-95.

Haynes, D. F. (2010). Lessons from Bosnia's Arizona Market: Harm to Women in a Neoliberalized Postconflict Reconstruction Process. En: University of Pennsylvania Law Review, Vol. 158, n. 6 , p.1779- 1829 . 
Justino P., L. M. (2011). Education and Conflict Recovery, The Case of Timor Leste. Policy Research Working Paper 5774. Banco Mundial, 65p.

Kreimer, A.; Muscat R.; Elwan A. y Arnold M. (2000a). Bosnia and Herzegovina: post-conflict reconstruction: Country Case Study Series, Publicaciones Banco Mundial, 107p.

Kreimer, A.; Collier P.; Scott C. y Arnold M. (2000b). Uganda: post-conflict reconstruction. Country Case Study Series, World Bank Publications, 73p.

Kumar, K.; Baldwin, H. y Benjamin, J. (2000), Aftermath: Women’s organization in post conflict El Salvador. USAID Evaluation Highlights n. 72 , 8p.

Laplante, L. (2007). Después de la verdad: demandas para reparaciones en el Perú, Poscomisión de la verdad y la reconciliación. En: Antípoda, n. 4, p. 119-145.

Lemmon, G. T. (2012). Entrepreneurship in postconflict zones, Working paper, Council on Foreign Relations, 21p.

Lyer, L. y Santos, I. (2012). Creating jobs in South Asia's conflict zones. World Bank Policy Research Working Paper n. $6104,54 \mathrm{p}$.

Lynch, K.; Maconachie, R.; Binns, T.; Tengbe, P. y Bangura, K. (2013). Meeting the urban challenge? Urban Agriculture and Food Security in Post-Conflict Freetown, Sierra Leone. En: Applied Geography, Vol. 36, n..$^{\circ}$, p. 31-39.

Massaquoi, W. N. (2007). Women and Post-Conflict Development: A Case Study on Liberia (Doctoral dissertation), Massachusetts Institute of Technology, Boston, Massachusetts, United States, 126p.

Menjívar C. y Agadjanian V. (2007), Men's Migration and Women's Lives: Views from Rural Armenia and Guatemala. En: Social Science Quaterly, Vol. 88, n. ${ }^{\circ}$ 5, p. 1243-1262.

McMahon, P. C. (2004). Rebuilding Bosnia: a model to emulate or to avoid? En: Political Science Quarterly, Vol. 119, n. 4, p. 569-593.

Nasi, C. y Rettberg, A. (2005). Los estudios sobre conflicto armado y paz: un campo en evolución permanente. En: Colombia Internacional, n. ${ }^{\circ}$ 62, p. 64-85.

Ohanyan A. (2002). Post Conflict Global Governance: The Case of Microfinance Enterprise Networks in Bosnia and Herzegovina. En: International Studies Perspectives, Vol. 3, n. ${ }^{\circ}$, p. 396-416.

Organización Internacional del Trabajo - OIT (2010). La recuperación económica local en situaciones de posconflicto. Programa de respuesta a las Crisis y Reconstrucción (OIT/ CRISIS), 313p.

Programa de las Naciones Unidas para el Desarrollo - PNUD (2011). Informe Nacional de Desarrollo Humano. Bogotá: PNUD, 446p.

Randall, S. (2005). The demographic consequences of conflict, exile and repatriation: A case study of Malian Tuareg. En: European Journal of Population/Revue Européenne de Démographie, Vol. 21, n. $2 / 3$, p. $291-320$

Richani, N. (2010). State Capacity in Post Conflict Settings: Explaining Criminal Violence in El Salvador and Guatemala. En: Civil Wars, Vol. 12, n. ${ }^{\circ}$ 4, p. $431-455$. 
Rugumamu, S. y Gbla, O. (2003). Studies in Reconstruction and Capacity Building in Post-Conflict Countries in Africa, some Lessons of Experience from Rwanda. Harare, Zimbabwe: The African Capacity Building Foundation, 63p.

Smet, S. (2009). A Window of Opportunity-Improving Gender Relations in Post-Conflict Societies: The Sierra Leonean Experience. En: Journal of Gender Studies, Vol. 18, n. 2, p. 147-163.

Tarway-Twalla, A. (2011). The Contribution of Grassroots Business to Postconflict Development in Liberia. En: Journal of Enterprising Communities: People and Places in the Global Economy, Vol. 5, n. $^{\circ}$, p. 58-67.

Tabak, S. (2011). False Dichotomies of Transitional Justice: Gender, Conflict and Combatants in Colombia. En: International Law and Politics, Vol. 44, p. 103-156.

Thomson, F. (2011). The Agrarian Question and Violence in Colombia: Conflict and Development. En: Journal of Agrarian Change, Vol. 11, n. ${ }^{\circ}$ 3, p. 321-356.

Thorsell, S. (2013). Towards People-Centred Economic Reintegration? An Analysis of the Economic Reintegration Strategy of Demobilised Combatants in Colombia. En: Colombia Internacional, Vol. 77, p. 177-215.

Tobias, J. M. y Boudreaux, K. C. (2011). Entrepreneurship and Conflict Reduction in the Post-Genocide Rwandan Coffee Industry. En: Journal of Small Business \& Entrepreneurship, Vol. 24, n. ${ }^{\circ}$ 2, p. 217-242.

UNDP (2010). Leadership and Change in Post-Conflict States: A Case Study of Liberia. United Nations Development Programme, Global Event Working paper, 31p.

Vélez, A. y Insuasty, A. (2017). Experiencias de economía solidaria en escenarios de postconflicto. Medellín: Editorial Kavilando, 77p.

Wei, D. (1996). Bosnia and Herzegovina - Toward Economic Recovery. Publicaciones del Banco Mundial, 68p. 